\title{
A nested grid formulation for chemical transport over Asia: Applications to CO
}

\section{Citation}

Wang, Yuxuan X. Michael B. McElroy, Daniel J. Jacob, and Robert M. Yantosca. 2004. “A Nested Grid Formulation for Chemical Transport over Asia: Applications to CO." Journal of Geophysical Research 109 (D22). doi:10.1029/2004jd005237.

\section{Published Version}

doi:10.1029/2004JD005237

\section{Permanent link}

http://nrs.harvard.edu/urn-3:HUL.InstRepos:14121840

\section{Terms of Use}

This article was downloaded from Harvard University's DASH repository, and is made available under the terms and conditions applicable to Other Posted Material, as set forth at http:// nrs.harvard.edu/urn-3:HUL.InstRepos:dash.current.terms-of-use\#LAA

\section{Share Your Story}

The Harvard community has made this article openly available.

Please share how this access benefits you. Submit a story.

\section{Accessibility}




\title{
A nested grid formulation for chemical transport over Asia: Applications to CO
}

\author{
Yuxuan X. Wang, Michael B. McElroy, Daniel J. Jacob, and Robert M. Yantosca \\ Department of Earth and Planetary Science and Division of Engineering and Applied Sciences, Harvard University, \\ Cambridge, Massachusetts, USA
}

Received 15 July 2004; revised 9 August 2004; accepted 30 August 2004; published 24 November 2004.

[1] A global three-dimensional chemical transport model (GEOS-CHEM) was modified to permit treatment of a limited spatial regime with resolution higher than that adopted for the global background. Identified as a one-way nested grid formulation, the model was applied to a simulation of $\mathrm{CO}$ over Asia during spring 2001. Differences between results obtained using the nested grid (resolution $1^{\circ} \times 1^{\circ}$ ), the coarse global model (resolution $4^{\circ} \times 5^{\circ}$ ), and the intermediate global model (resolution $2^{\circ} \times 2.5^{\circ}$ ) are discussed. The higher-resolution model allows for more efficient, advection-related, ventilation of the lower atmosphere, reflecting the significance of localized regions of intense upward motion not resolved in a coarser-resolution simulation. Budget analysis suggests that upward transfer to higher altitudes through large-scale advection provides the major sink for $\mathrm{CO}$ below $4 \mathrm{~km}$. Horizontal advection, mainly through the north boundary, contributes a net source of $\mathrm{CO}$ to the window domain despite the polluted nature of the study region. The nested-grid model is shown to provide good agreement with measurements made during the Transport and Chemical Evolution over the Pacific (TRACE-P) campaign in spring 2001, notably better than the low-resolution model in simulating frontal lifting process and differences across the boundary separating the regions of cyclonic and anticyclonic flow. The high-resolution window approach also allows us to differentiate transport mechanisms for individual subregions of China on a much finer scale than was possible previously. Suggestions are made as to how to allow for subgrid vertical advective motions in the low-resolution model through a carefully designed and broadly tested eddy diffusion treatment. INDEX TERMS: 0368 Atmospheric Composition and Structure: Troposphere - constituent transport and chemistry; 0365 Atmospheric Composition and Structure: Troposphere-composition and chemistry; 3364 Meteorology and Atmospheric Dynamics: Synoptic-scale meteorology; KEYWORDS: CO, model resolution, nested grid

Citation: Wang, Y. X., M. B. McElroy, D. J. Jacob, and R. M. Yantosca (2004), A nested grid formulation for chemical transport over Asia: Applications to CO, J. Geophys. Res., 109, D22307, doi:10.1029/2004JD005237.

\section{Introduction}

[2] Our understanding of the chemistry of the global troposphere has advanced significantly over the past twenty years. Several factors have contributed to this progress: first the commitment of resources to the acquisition of high quality observational and laboratory data; and, second, the development of credible models for the interpretation of these data.

[3] The observational data include long-term measurements of selected species at fixed locations, with particular emphasis on gases with potential to affect either climate or the abundance of stratospheric $\mathrm{O}_{3}$, notably $\mathrm{CO}_{2}, \mathrm{CH}_{4}$, $\mathrm{N}_{2} \mathrm{O}$, CFCs and HCFCs. These data have been complemented in recent years with results from a number of more focused initiatives designed specifically to improve our

Copyright 2004 by the American Geophysical Union. 0148-0227/04/2004JD005237\$09.00 understanding of the chemistry of the troposphere. These studies address the complex array of processes responsible for the production of $\mathrm{O}_{3}$ and for the removal from the atmosphere of a variety of species ranging from short-lived hydrocarbons and $\mathrm{CO}$ to the oxides of nitrogen and sulfur critical for the phenomenon of acid rain. They determine the abundance and distribution of $\mathrm{O}_{3}$ and to a large extent they set the lifetime for species such as $\mathrm{CH}_{4}$ and the HCFCs, regulating thus their influence on climate and the stratosphere.

[4] The chemistry of the troposphere is intrinsically threedimensional. It reflects the response of the atmosphere to a variety of sources both natural and anthropogenic. It involves a diversity of timescales ranging from nanoseconds $\left(\mathrm{O}\left({ }^{1} \mathrm{D}\right)\right)$ to years $\left(\mathrm{CH}_{4}\right)$. Spatial redistribution is critically important for species with lifetimes longer than a few weeks while local chemical processes may be taken as dominant for species with lifetimes shorter than a day or so. The approach to modeling the chemistry of the troposphere 
invokes a segregation of species according to lifetime. For shorter-lived species such as $\mathrm{OH}$ it is usually assumed in global models that concentrations are determined by a local balance of chemical production and loss (chemical equilibrium). Transport however is critically important for a number of the species involved in regulating this equilibrium, notably $\mathrm{O}_{3}, \mathrm{CO}$ and $\mathrm{NO}_{\mathrm{x}}$. The distribution of these species is determined by solving an appropriate set of three-dimensional chemical continuity equations, a formulation referred to as a chemical transport model (CTM). In this approach, properties of the background atmosphere (the distribution of pressure, temperature, clouds and water vapor, and details of the velocity field including convective overturning) must be specified independently.

[5] In early models, these properties were specified often by incorporating data obtained as by-products of general circulation models (GCMs) designed to study climate. The disadvantage in this case is that the resulting CTMs could be applied at best to simulate climatically averaged states of the atmosphere. They were less useful, however, when applied to interpret observations taken at a specific time. An important recent development involves use of meteorological data assimilated to describe conditions for specific times. GEOS-CHEM exemplifies this new class of CTM. It is driven by meteorological data provided by the Goddard Earth Observation System (GEOS) of the NASA Global Modeling and Assimilation Office (GMAO) [Schubert et al., 1993]. Details of the model are described by Bey et al. [2001a]. The model has been employed to simulate the chemistry of $\mathrm{O}_{3}, \mathrm{NO}_{\mathrm{x}}$ and VOC over North America [Fiore et al., 2002], the Middle East [Li et al., 2001], and the western Pacific [Liu et al., 2002]. It has been applied also to investigate paths for interregional transport of pollution using $\mathrm{CO}$ as a convenient tracer of this transport [Bey et al., 2001b; Liu et al., 2003]. In these latter studies, chemistry was treated off-line, that is to say fields of $\mathrm{OH}$ were not calculated concurrently but were specified independently based on previous runs with the full chemistry version of the model [Fiore et al., 2003].

[6] The present study is motivated by an ambition to develop a credible model for air quality over east Asia, specifically over China. It is part of a larger study at Harvard seeking to estimate costs to the Chinese economy associated with the complex impacts of air pollution on public health. The meteorology of the east Asian environment is controlled in large measure by the Asian monsoon with a general outflow of surface air from the continent in winter compensated by an inflow in summer. Prevailing winds over Hong Kong, for example, are typically from the northeast in winter, switching to the southwest in summer. Depending on the time of year, air quality over Hong Kong is subject thus to the influence of emissions not only from the Chinese mainland but also from sources in both northeast and southeast Asia [Lam et al., 2001; Liu et al., 1999]. To meet the objectives of our research, we require a model with moderately high spatial resolution over China and neighboring regions of east and southeast Asia. Lower resolution is acceptable elsewhere. To meet these requirements we describe here (in section 2) an elaboration of the GEOS-CHEM model, a nested grid approach, allowing for inclusion of a regional window with relatively high spatial resolution $\left(1^{\circ} \times 1^{\circ}\right)$ imbedded in a lower-resolution global context $\left(4^{\circ} \times 5^{\circ}\right)$. The global model is run as usual over the whole globe, including the nested domain. Results from the coarse global model simulation are used to drive the fineresolution model through boundary conditions defined by the low-resolution model, but not vice versa. The nesting here is thus only one-way. The nested model can either be run in parallel with the coarse grid, or separately as a regional model, provided boundary conditions from the global model have been archived with sufficient frequency. Compared to regional models with prescribed constant boundary conditions, the nested grid model has the advantage of allowing for accurate and time-varying boundary conditions. The influence of imported $\mathrm{CO}$ through dynamical boundary conditions is found to be nontrivial and will be discussed in section 3 .

[7] The nested grid approach is attractive in that a number of GCMs (ECMWF for example) are capable of providing meteorological data with a hierarchy of resolutions to drive a CTM. Significant effort [see, e.g., Alapaty et al., 1998] has been devoted to develop consistent mathematical techniques to facilitate mapping of meteorological data from one resolution to another. Early applications of the nested grid approach focused mainly on regional studies of acid deposition [Pleim et al., 1991; Jakobs et al., 1995; Kim and Cho, 1999]. These studies showed that with higher resolution the nested model allows for an improved simulation not only of $\mathrm{SO}_{2}$ but also for the range and spatial variability of observed acid deposition. Langmann et al. [2003] used a nested grid incorporating a global to mesoscale model chain to study the influence of the global-scale ozone background on concentrations of ozone observed during a summer smog episode in Europe. The global model was coupled in this case to the mesoscale model using a oneway nesting procedure (that is to say, the global model was employed to define boundary conditions for the mesoscale model but the mesoscale model was not allowed to feedback on the global model). They found that the simulation of the smog episode was improved when the mesoscale model adopted boundary conditions defined by the global model. The mesoscale and global models employed in this study, however, used different meteorological fields, employed different chemical mechanisms, and differed also in their treatment of transport. It is difficult under these circumstances to assess the significance of the improvements realized as a consequence simply of increasing the spatial resolution.

[8] As defined above, the nested grid approach presumes a window with high spatial resolution imbedded in a global model with lower resolution. In most cases, resolution within the high-resolution window is fixed at some uniform value, say $1^{\circ}$ by $1^{\circ}$, and fixed also at some constant value in the lower-resolution global background. An alternate approach would use spatially variable resolution with progressively closer spacing of grid points in the region of interest. This defines what is referred to as a stretched grid approach. A stretched grid model has an important advantage over the more common nested grid approach in that the lateral boundary conditions required to define the interface between the window region and the external medium in the nested grid model are unnecessary with the stretched grid formulation. On the other hand, stretched grid models 


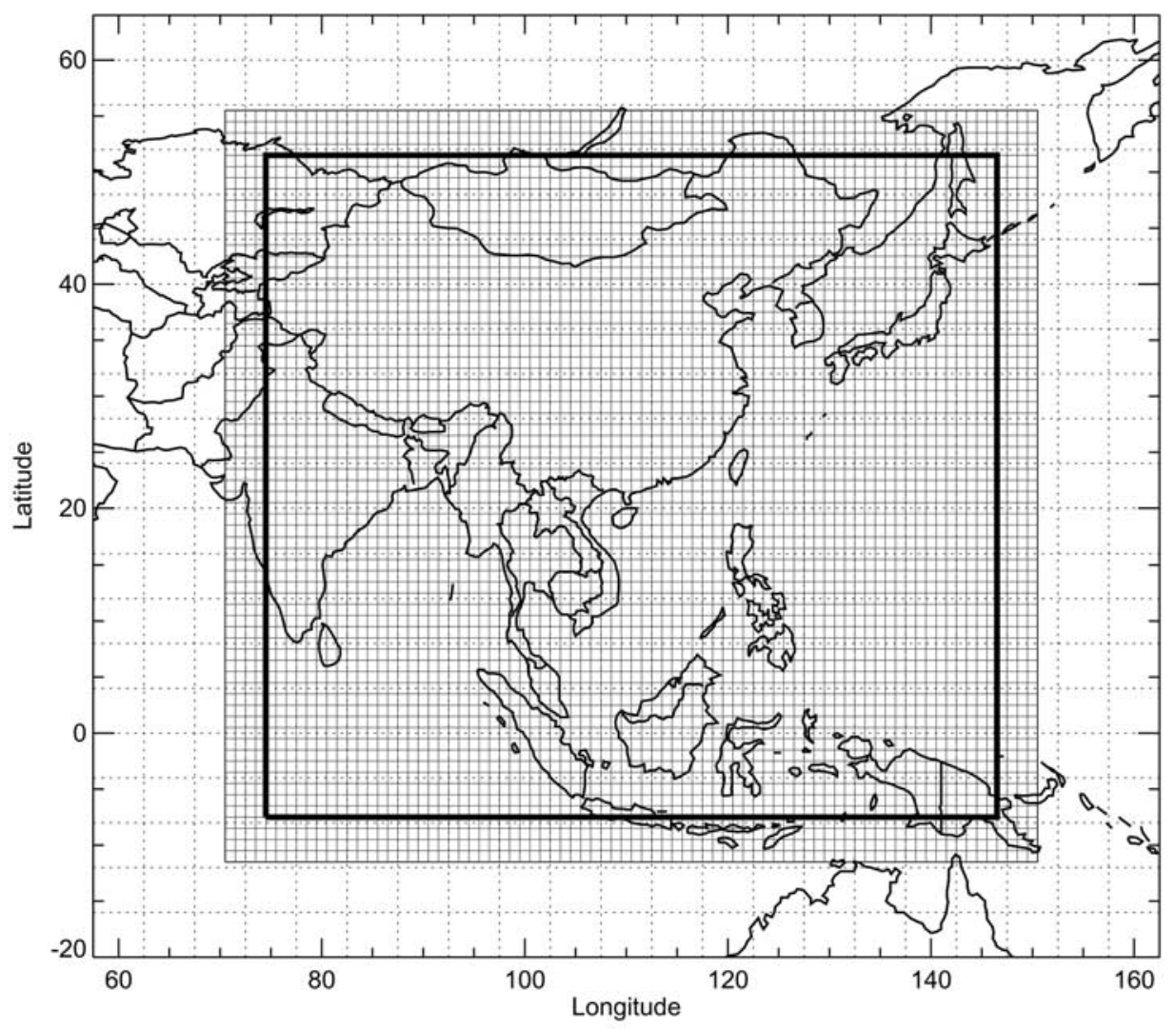

Figure 1. Schematic representation of the nested window. The black thick line is the actual boundary of the nested model. The grid boxes outside the black rectangle in the fine-resolution domain define the buffer zone for boundary conditions. The $1^{\circ} \times 1^{\circ}$ model grid and $4^{\circ} \times 5^{\circ}$ model grid are confluencecentered (e.g., $40.5^{\circ}-41.5^{\circ} \mathrm{N}, 115.5^{\circ}-116.5^{\circ} \mathrm{E}$ for $1^{\circ} \times 1^{\circ} ; 40^{\circ}-44^{\circ} \mathrm{N}, 112.5^{\circ}-117.5^{\circ} \mathrm{E}$ for $4^{\circ} \times 5^{\circ}$ ). Thus the fine grid cells are aligned with the coarse grid bounds in longitude and offset by half a cell in latitude.

require inputs of meteorological data on compatible spatially variable grids, an option that is unlikely to be available, given the expense of running a GCM, except under special circumstances [Allen et al., 2000].

[9] The nested grid approach adopted here is described in section 2. The resolution of the high-resolution window is set at $1^{\circ} \times 1^{\circ}$ and the window is imbedded in a global model with a resolution of $4^{\circ} \times 5^{\circ}$. The nested model is applied to an analysis of $\mathrm{CO}$ over the period January to April 2001. Over this time interval for the region of interest here (east Asia), the lifetime of $\mathrm{CO}$ ranges from weeks to months. CO behaves thus similar to a passive tracer. As a consequence, the distribution of $\mathrm{CO}$ is determined primarily by transport and by the spatial pattern of sources. A specific objective of the present investigation is to examine the sensitivity of results to the choice of resolution for the transport model. Differences between results obtained with the window model (localized $1^{\circ} \times 1^{\circ}$ resolution) and the lower-resolution global model (uniform $4^{\circ} \times 5^{\circ}$ resolution) are discussed in section 3. For comparison, results obtained from an intermediate case, the global model at $2^{\circ} \times 2.5^{\circ}$ resolution, are also included in section 3 . The nested model is applied to an analysis of the NASA TRACE-P (The Transport and Chemical Evolution over the Pacific) aircraft observations in section 4, with a specific objective to examine the outflow of CO from Asia. Summary remarks are presented in section 5 .

\section{Nested Modeling Approach}

[10] Properties of the global GEOS-CHEM model are described by Bey et al. [2001a]. For present purposes we chose to use GEOS-CHEM version 5.02 (see http://wwwas.harvard.edu/chemistry/trop/geos). This representation of the model has been shown to conserve both tracer mass and mixing ratio. As meteorological input we adopted the 2001 GEOS-3 data set. Details of this data source are presented elsewhere [Fiore et al., 2002; Liu et al., 2003].

[11] The structure of the nested window adopted for the present study is illustrated in Figure 1. The window domain $\left(70^{\circ} \mathrm{E}-150^{\circ} \mathrm{E}, 11^{\circ} \mathrm{S}-55^{\circ} \mathrm{N}\right)$ includes all of China, its neighboring countries, and a significant portion of the northwestern Pacific. As noted above, the resolution of the window region is set at $1^{\circ} \times 1^{\circ}$ and the window is imposed on a global background at a resolution of $4^{\circ} \times 5^{\circ}$. The GEOS-3 data are presented on a $1^{\circ} \times 1^{\circ}$ grid. As such they can be applied directly to the window region adopted for the present study. The GEOS data were degraded in a consistent fashion to accommodate the coarser $\left(4^{\circ} \times 5^{\circ}\right)$ resolution of the global model. For quantities defined with respect to 
individual grid units (precipitation rates for example), the GEOS data were combined (added) to develop the appropriate input for the lower-resolution model. For quantities defined with respect to unit area (surface pressure, horizontal winds, and temperature for example), this was accomplished by averaging over the appropriate number of high-resolution grids. A pressure weighting procedure was applied to degrade horizontal winds from $1^{\circ} \times 1^{\circ}$ to lower resolutions $\left(4^{\circ} \times 5^{\circ}\right.$ or $\left.2^{\circ} \times 2.5^{\circ}\right)$ in order to conserve mass fluxes between two resolutions. This is a correction to previous GEOS-CHEM global studies where horizontal winds are degraded by a simple areaweighting procedure. However, we found that the differences between degraded low-resolution winds obtained from the pressure-weighting and area-weighting procedure are generally small, probably due to the adoption of a pressure-fixer scheme in the GEOS-CHEM model (described below), and that inadequate regridding would not significantly affect previous GEOS-CHEM studies.

[12] GEOS-CHEM uses a terrain-following sigma coordinate, defined as $\sigma \equiv p / p_{s}$ where $p_{s}$ denotes the pressure at the surface, to specify the variation of quantities in the vertical dimension. The vertical resolution of the model in the window region was taken as the same as the resolution employed by the global model. This allows for 30 vertical layers specified by sigma surfaces extending up to $0.1 \mathrm{hPa}$, with an average of nine layers employed to define the surface boundary regime below $2 \mathrm{~km}$. From the Tibetan Plateau and Himalayas in the west to the Pacific Ocean in the east, the Asian continent exhibits some of the most complex terrain in the world. China's topography features high plateaus to the west with low plains to the east. Surface geopotential heights defined by the GEOS-3 data at resolutions of $1^{\circ} \times 1^{\circ}$ and $4^{\circ} \times 5^{\circ}$ are provided in Figures $2 \mathrm{a}$ and $2 \mathrm{~b}$. A high-resolution ( 3 arc minute grid) representation of topography is displayed for comparison purposes in Figure 2c (see ftp://ftp.ngdc.noaa.gov/GLOBE_DEM/ pictures/GLOBALeb3colshade.jpg). The major differences between Figures $2 \mathrm{a}$ and $2 \mathrm{~b}$ reflect contrasts in the representation of the spatial scales for significant changes in terrain. The higher-resolution model is more successful also in its depiction of a number of specific topographic features, notably the Sichuan Basin (at approximately $30^{\circ} \mathrm{N}, 105^{\circ} \mathrm{E}$ ) immediately to the east of Tibetan Plateau, Tai Mountain (in the vicinity of $35^{\circ} \mathrm{N}, 118^{\circ} \mathrm{E}$ ) in the otherwise low-elevation North China Plain, and the Wuyi Mountain Chain (around $25^{\circ} \mathrm{N}$ and $118^{\circ} \mathrm{E}$ ) on the south east coast. The importance of vertical motions driven by changes in terrain will be discussed further in section 3 .

[13] The GEOS-CHEM model uses the flux form semiLangrangian (FFSL) advection scheme of Lin and Rood [1996], and the moist convective mixing scheme of Allen et al. [1996] applied to the GEOS convective updraft, entrainment, and detrainment mass fluxes. Rapid and complete vertical mixing within the GEOS-diagnosed mixed layer is assumed in the model. These mixing depths are diagnosed by the GEOS Data Assimilation System as the pressure level where turbulent kinetic energy is $10 \%$ of the surface layer value [Allen et al., 1996]. The problem pointed out by Jöckel et al. [2001] for flux-form schemes is addressed by adopting the pressure-fixer scheme developed by CameronSmith et al. (see http://asd.llnl.gov/pfix/index.html) to achieve consistency between the surface pressures calculated by the advection scheme of the CTM and the original meteorological fields. The pressure-fixer adjusts the horizontal wind fields to ensure that the CTMs surface pressure fields follow the surface pressure of the meteorological fields at the end of each time step. The corrective horizontal mass-fluxes generated by the pressure-fixer are distributed in the vertical in proportion to the change in sigma coefficient across each layer; therefore, they do not induce any vertical wind.

[14] Boundary conditions for the window region were implemented as follows. The four outermost rows and columns of the high-resolution grid were used to delineate a buffer zone separating low and high-resolution portions of the model. The innermost rows and columns of this buffer zone (indicated by the thick black line in Figure 1) were taken to define the physical boundary of the window regime. The time step for the model in the low-resolution regime $\left(4^{\circ} \times 5^{\circ}\right)$ is $30 \mathrm{~min}$, reduced to $10 \mathrm{~min}$ in the highresolution region $\left(1^{\circ} \times 1^{\circ}\right.$ horizontal resolution). Since the numerical scheme used to treat advection is biased to the upstream direction, boundary elements of the nested window region must be treated with care in regions where the flow is directed into the nested domain. The direction of the wind field was used to identify whether the flow was directed into or out of the nested window within the physical boundary (inside the thick line in Figure 1). In regions of inflow, mixing ratios of tracers in the buffer zone exterior to the physical boundary were used to provide necessary upstream information. Mixing ratios for bufferzone fine grids are always taken from the coarse-resolution simulation through an area-weighting, grid-filled procedure described below, regardless of the inflow or outflow condition. Mixing ratios obtained for specific grid elements of the low-resolution model were used for buffer-zone fine grids that are located completely inside the coarse grid. For fine grids across the boundaries of several coarse grids, mean mixing ratios for these coarse grids, weighted by area occupied, were used. This procedure was implemented every three hours since the highest temporal resolution of the GEOS-3 meteorological data is 3 hours. Increasing the updating frequency to $30 \mathrm{~min}$ (the coarse grid time step) was found to have only a small impact on the boundary conditions for $\mathrm{CO}$, suggesting that boundary conditions are mainly responsive to synoptic features that are adequately represented by the 3 hour frequency. If the upstream connection extended beyond the buffer zone, mixing ratios were specified as defaults. As discussed below, however, this situation was never encountered.

[15] The advection algorithm employed by the model requires that the Courant number in north-south direction $\left(C^{y}=v \Delta t / \Delta y\right.$, where $v$ is meridional wind velocity, $\Delta t$ is the dynamic time step and $\Delta y$ is the longitudinal grid size) should not exceed 1. The Courant number in the west-east direction $\left(C^{x}=u \Delta t / \Delta x\right.$, where $u$ is zonal wind velocity, $\Delta x$ is the latitudinal grid size) may be greater than 1 in regions close to the poles. FFSL is extended to regions with large $C^{x}$ by a separation between an integer and fractional flux [Lin and Rood, 1996]. The choice of $10 \mathrm{~min}$ as the advection time step in the $1^{\circ} \times 1^{\circ}$ resolution region satisfies the $\mathrm{C}^{\mathrm{y}}<1$ requirement everywhere. By definition, the Courant number for any partic- 
a) Terroin Elevations (1×1)

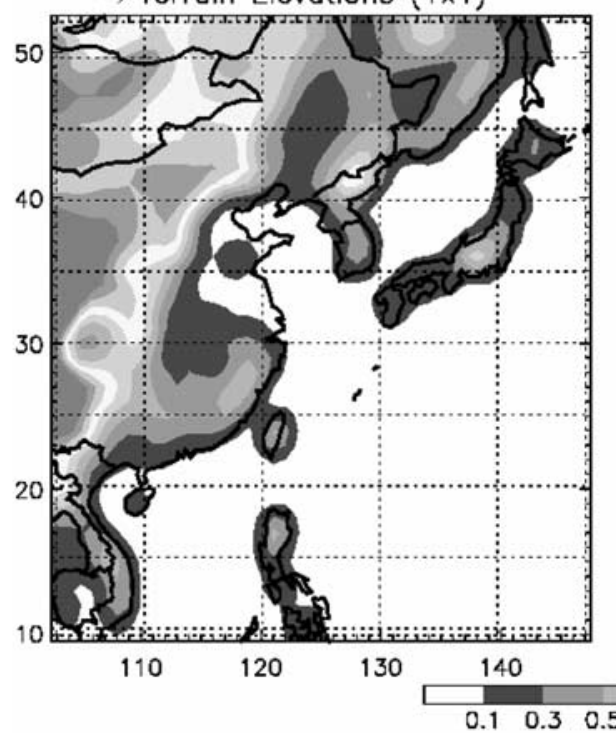

b) Terroin Elevations (4×5)

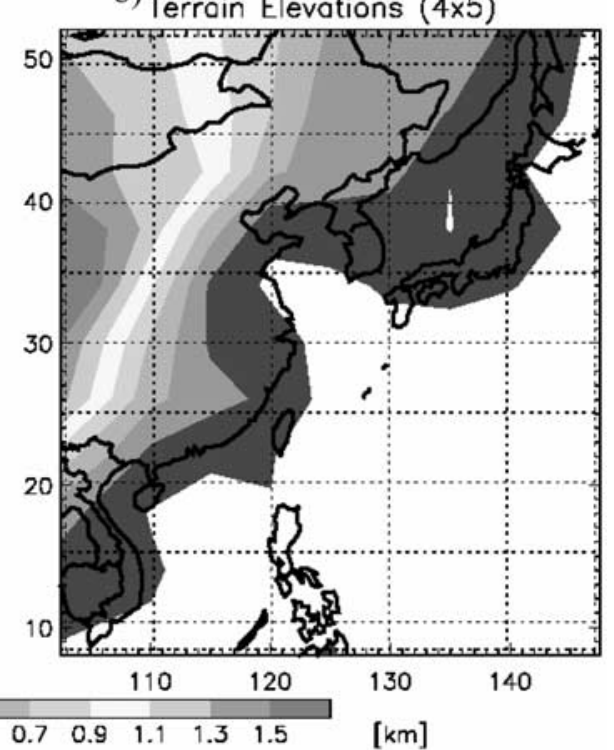

c) Terrain elevations at high resolution

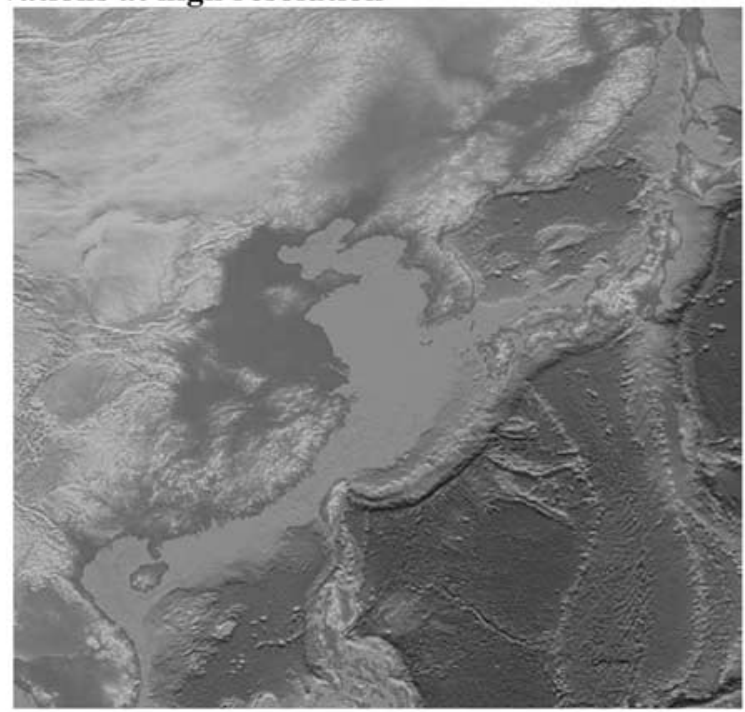

Figure 2. GEOS terrain elevations for the window region at (a) $1^{\circ} \times 1^{\circ}$ and (b) $4^{\circ} \times 5^{\circ}$ resolution. (c) High-resolution (3 arc-minute grid) topography image from NOAA National Data Centers is shown for comparison (ftp://ftp.ngdc.noaa.gov/GLOBE_DEM/pictures/GLOBALeb3colshade.jpg). See color version of this figure at back of this issue.

ular grid is a measure of the extent to which the grid can be influenced by advection from upwind grids in a single time step. For example, a Courant number of 2 for a particular grid $\mathrm{X}$ indicates that information from two grids upwind would be required to calculate advection related changes in concentration at $\mathrm{X}$. For the north and south boundaries of the window region, a one-grid-wide buffer zone should suffice since $C^{\mathrm{y}}$ is always less than one. Since the window region is located at relatively low latitude, the west-east Courant number is normally also less than 1. Exceptions would arise if the west-east wind speed were to exceed $107 \mathrm{~m} / \mathrm{s}$ (Courant number of 1 for the smallest grid size of $64 \mathrm{~km}$ ). The four-grid width buffer zone adopted here for the west-east dimension should suffice for all conditions encountered in practice.
It would need to be extended only if the west-east wind speed were to exceed $430 \mathrm{~m} / \mathrm{s}$, an unlikely possibility for the midlatitude troposphere.

[16] It is important to note that the methodology adopted for the treatment of boundary conditions in the nested grid model must depend ultimately on the nature of the numerical scheme selected for simulation of advection by the CTM. Problems can arise for example in the outflow region if the numerical scheme requires information on the downstream environment. Failure to account for this complication can lead to physically unrealistic results, numerically driven reflection of tracer from boundaries for example. Pleim et al. [1991] and Jakobs et al. [1995] addressed this complication by specifying a condition of zero net flux at the outflow boundary. Use of an exclusive upstream ap- 
proach for the treatment of advection in the GEOS-CHEM model obviates the need for a special treatment of boundary conditions in the outflow region.

[17] The results from the $4^{\circ} \times 5^{\circ}$ coarse global model simulation employed here were used to drive the fineresolution model through boundary conditions defined by the low-resolution model, but not vice versa. We refer to this approach as a one-way nesting procedure. An important test of our one-way nesting model was implemented by considering the limiting case for which the resolution of the window region was selected to be identical to that of the background global model. We verified that results from the nested grid version of the model were identical to those obtained using the global model (the conventional version of GEOS-CHEM), a necessary if not sufficient condition for validation of the nested grid approach.

\section{Applications to $\mathrm{CO}$}

[18] A CO-only simulation was conducted using the global and nested model for the spring of 2001 with specified $\mathrm{OH}$ fields (described below). For comparison, we implemented global simulations with both $4^{\circ} \times 5^{\circ}$ and $2^{\circ} \times 2.5^{\circ}$ resolution, which we refer to as the coarse global model and the intermediate global model, respectively. The $2^{\circ} \times 2.5^{\circ}$ global model differs from the $4^{\circ} \times 5^{\circ}$ global model only in terms of horizontal resolution. We compare in this section results obtained using the nested grid model with results from the lower-resolution global model. Our specific objective is to explore differences relating to the higher spatial resolution available in the window region of the nested grid model. We choose to apply our analysis to $\mathrm{CO}$ recognizing that results in this case should be insensitive to differences in the simulation of the chemical processes responsible for removal of $\mathrm{CO}$ given the relatively long lifetime of the gas over the time interval (January to March) selected for our study. Differences may be attributed thus entirely to consequences of the higherresolution specification of sources and to differences in the treatment of transport as simulated using the nested grid formulation.

[19] We used archived monthly mean $\mathrm{OH}$ concentration fields from a previous global $\mathrm{O}_{3}-\mathrm{NO}_{\mathrm{x}}-\mathrm{NMVOC}$ simulation at $2^{\circ} \times 2.5^{\circ}$ resolution for 2001 [Fiore et al., 2003]. $\mathrm{OH}$ concentrations on a $2^{\circ} \times 2.5^{\circ}$ grid were mapped on to a $4^{\circ} \times$ $5^{\circ}$ and $1^{\circ} \times 1^{\circ}$ grid in a consistent fashion explained below, leading to the same distribution of $\mathrm{OH}$ for both grids. A simple area-weighting averaging was used to generate $\mathrm{OH}$ fields from a $2^{\circ} \times 2.5^{\circ}$ grid to a $4^{\circ} \times 5^{\circ}$ grid, while the area-weighting, grid-filled procedure was applied from a $2^{\circ} \times 2.5^{\circ}$ grid to a $1^{\circ} \times 1^{\circ}$ grid (section 2$)$.

[20] Emissions of $\mathrm{CO}$ resulting from combustion of fossil and biofuels over the window region were taken from Streets et al. [2003]. Their analysis allowed for the seasonal variation of emissions over central, south and north China. For emissions associated with fossil and biofuels over the rest of the world we adopted inventories reported by Duncan et al. [2003] and Yevich and Logan [2003] respectively. Emissions due to biomass burning, available on a daily basis for the TRACE-P period, were taken from Heald et al. [2003]. We accounted also for secondary sources of $\mathrm{CO}$ associated with oxidation of methane, isoprene, and other volatile organic compounds (VOCs) using results reported by Palmer et al. [2003]. In all cases, emissions were defined with respect to a $1^{\circ} \times$ $1^{\circ}$ grid, with degree confluence points at the corners (e.g., $\left.40^{\circ}-41^{\circ} \mathrm{N}, 115^{\circ}-116^{\circ} \mathrm{E}\right)$. The $1^{\circ} \times 1^{\circ}$ emissions data sets were regridded to match the $1^{\circ} \times 1^{\circ}$ model grid position since the $1^{\circ} \times 1^{\circ}$ model grid is confluencecentered (e.g., $40.5^{\circ}-41.5^{\circ} \mathrm{N}, 115.5^{\circ}-116.5^{\circ} \mathrm{E}$ ). The emissions data sets were averaged spatially to accommodate the lower $\left(4^{\circ} \times 5^{\circ}\right.$ or $\left.2^{\circ} \times 2.5^{\circ}\right)$ resolution invoked for the region external to the window.

[21] Composite emissions for the window region are presented in Figure $3 \mathrm{a}$ for the higher-resolution $1^{\circ} \times 1^{\circ}$ representation. The data displayed here refer to averages for March 2001. The relatively high intensity of emissions in southeast Asia and India is due to seasonal burning of biomass. Emissions are elevated also in a number of the more industrialized, more densely populated, regions of China: notably parts of northern China centered in the Beijing-Tianjin area (around $40^{\circ} \mathrm{N}, 115^{\circ} \mathrm{E}$ ); northeastern China near Shenyang $\left(42^{\circ} \mathrm{N}, 124^{\circ} \mathrm{E}\right)$; the Yangtze River Delta near Shanghai $\left(32^{\circ} \mathrm{N}, 122^{\circ} \mathrm{E}\right)$; the Pearl River Delta near Guangzhou $\left(22^{\circ} \mathrm{N}, 114^{\circ} \mathrm{N}\right)$; and the Sichuan Basin (in the vicinity of $30^{\circ} \mathrm{N}, 105^{\circ} \mathrm{E}$ ). While area-wide emissions are the same, the pattern of emissions is more heterogeneous with the fine-resolution model as compared to the coarseresolution model, reflecting the averaging procedure applied in deriving the data for the latter case. The heterogeneity is illustrated for three specific regions (Beijing-TianjinShenyang, the Pearl River Delta and the Sichuan Basin) in Figures $3 \mathrm{~b}-3 \mathrm{~d}$.

[22] To avoid transients associated with initial conditions, the coarse-resolution global models were run for a 15 -month period beginning 1 January 2000. Results for the end of year 2000 were saved and interpolated onto the $2^{\circ} \times$ $2.5^{\circ}$ and $1^{\circ} \times 1^{\circ}$ grid to provide initial conditions for the intermediate global model and the nested grid model. Three models were run from January 2001 to April 2001. Boundary conditions for the nested grid model were provided by the coarse global model (i.e., $4^{\circ} \times 5^{\circ}$ resolution). Results will be presented for March 2001 allowing sufficient time for the high-resolution model to adjust to transients introduced by the initialization of the model on 1 January 2001.

[23] Spatial distributions of $\mathrm{CO}$ mixing ratios (ppb) averaged over the altitude interval $0-2 \mathrm{~km}$ are presented in Figure 4. The figure includes results from the highresolution nested model (Figure 4a), the coarse global model (Figure $4 \mathrm{~b}$ ), and the intermediate global model (Figure 4c). Spatial patterns are similar for the three models with highest concentrations indicated for regions of high emission, notably for central and eastern China, India and southeast Asia. Peaks over China are attributed mainly to combustion of fossil and biofuels. Seasonal burning of biomass is primarily responsible for the peaks over India and southeast Asia. Vertical profiles of $\mathrm{CO}$ obtained from the three models are presented in Figure 5, for central China (in the vicinity of $30^{\circ} \mathrm{N}$, between $100^{\circ} \mathrm{E}$ and $120^{\circ} \mathrm{E}$, outlined by the white brackets in Figure 4) in Figure 5a and for the entire window region in Figure 5b. Mixing ratios of $\mathrm{CO}$ predicted by the coarse global model are significantly larger than for the high-resolution nested model at lower altitudes. 


\section{a) CO emissions for Mar 2001 (1x1)}
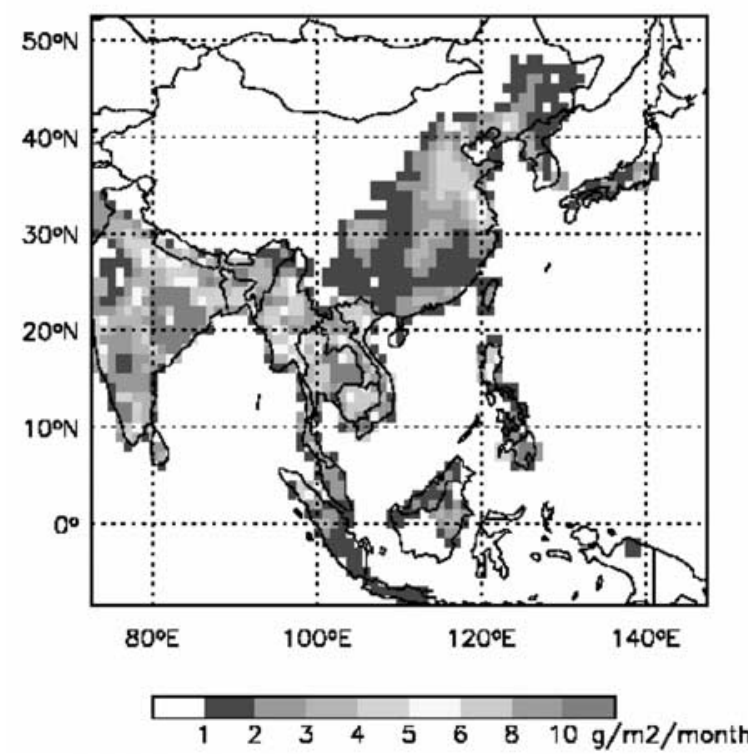

b) North and NE. China (4x5)

c) Pearl River Delta $(4 \times 5)$

d) Sichuan Basin $(4 \times 5)$
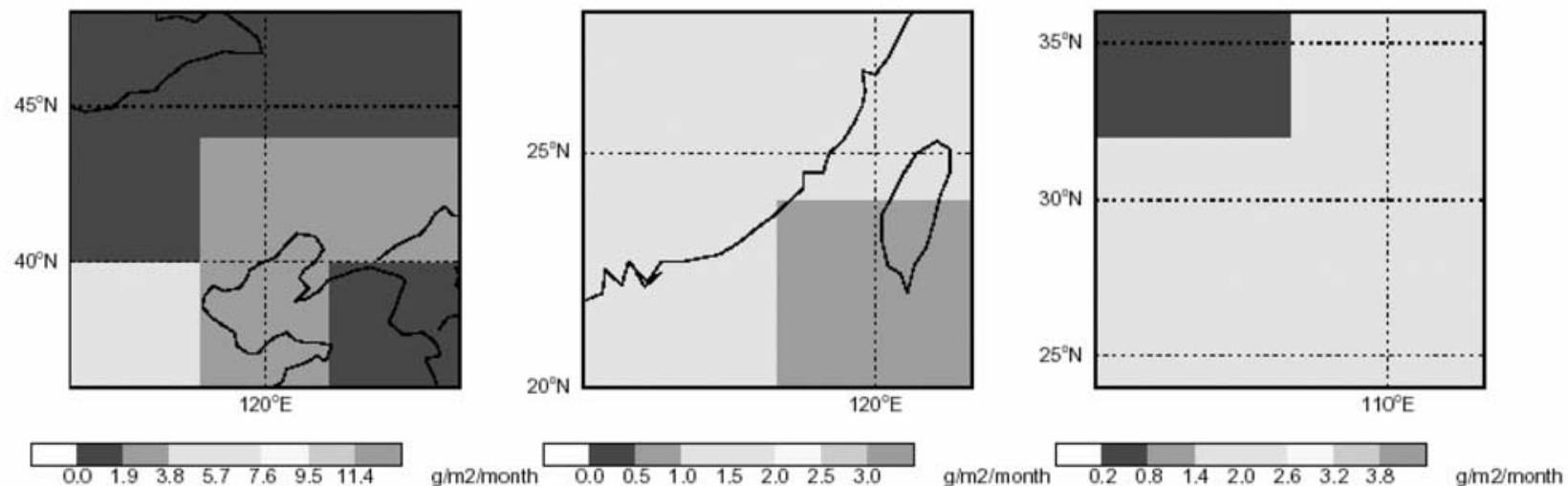

North and NE. China $(1 \times 1)$

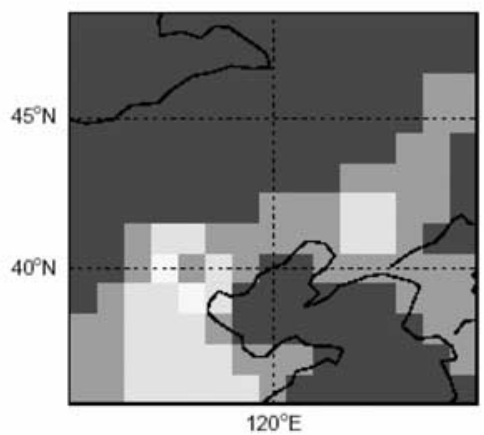

Pearl River Delta $(1 \times 1)$

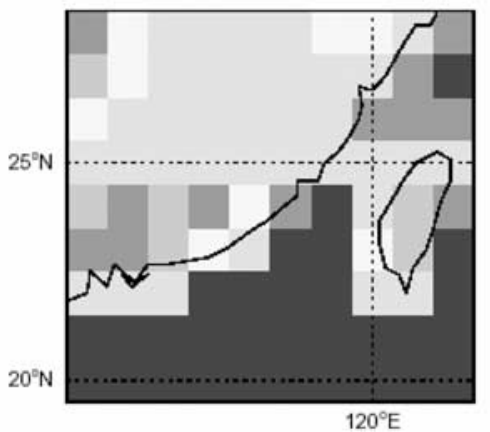

Sichuan Basin (1x1)

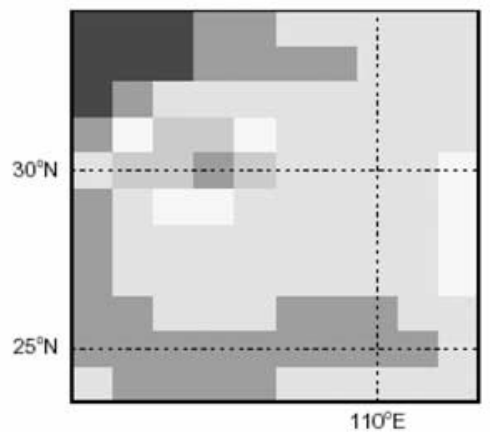

Figure 3. (a) Total $\mathrm{CO}$ emissions for the window region, represented by the $1^{\circ} \times 1^{\circ}$ nested model. Comparison of composite $\mathrm{CO}$ emissions at $1^{\circ} \times 1^{\circ}$ and $4^{\circ} \times 5^{\circ}$ resolution for several selected grids in (b) north and northeastern China, (c) Pearl River Delta, and (d) Sichuan Basin. Units are $\mathrm{g} / \mathrm{m}^{2} / \mathrm{month}$. Note that the color scale is different in each panel. See color version of this figure at back of this issue. 
(a) Mar.2001 CO mixing ratio ( $0-2 \mathrm{~km}, 1 \times 1)$

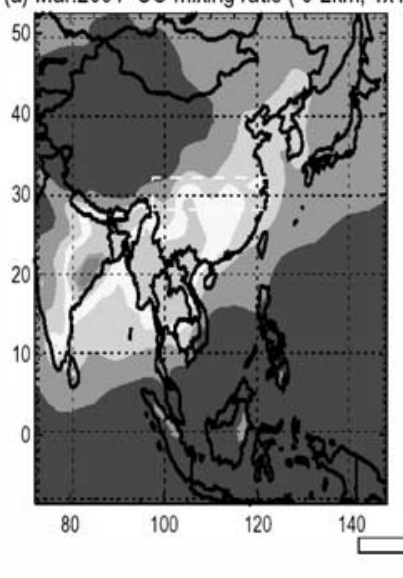

(b) Mar.2001 (0-2km, 4x5)

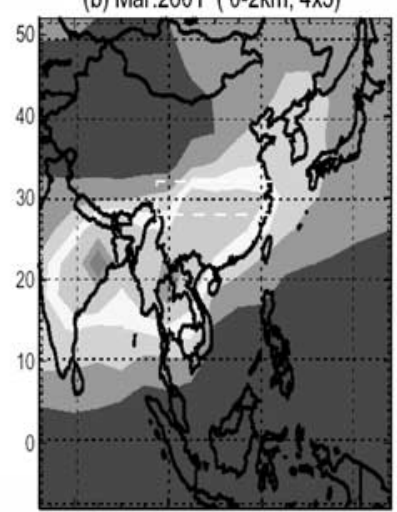

(c) Mar.2001 (0-2km, 2x25)

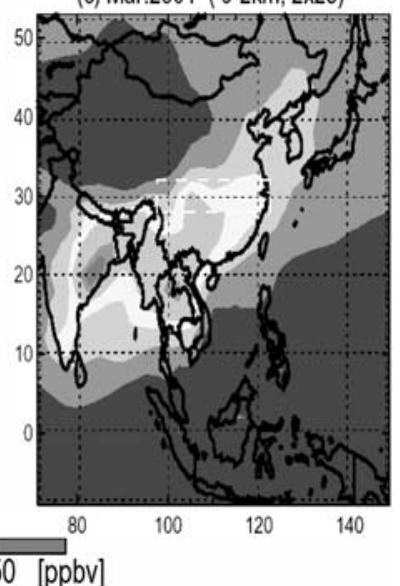

Figure 4. Comparisons of $\mathrm{CO}$ mixing ratios averaged between 0 and $2 \mathrm{~km}$ for March 2001, simulated by (a) the fine-resolution $\left(1^{\circ} \times 1^{\circ}\right)$ nested model, (b) the coarse-resolution $\left(4^{\circ} \times 5^{\circ}\right)$ global model, and (c) the intermediate-resolution $\left(2^{\circ} \times 2.5^{\circ}\right)$ global model. The central China region is defined by the dashed white rectangle in each panel. See color version of this figure at back of this issue.

The discrepancy extends to as high as $5 \mathrm{~km}$ over central China (Figure 5a) and, even when results are averaged over the entire window region (Figure 5b), the difference persists although it is restricted in this case to a somewhat smaller altitude interval $(0-2 \mathrm{~km})$. Mixing ratios of $\mathrm{CO}$ obtained from the intermediate global model $\left(2^{\circ} \times 2.5^{\circ}\right)$ lie between the coarse global model and the nested grid model, closer to the latter. The following discussion, largely focused on analyzing the differences between the nested grid and coarse global model, should apply generally to the differences between the $2^{\circ} \times 2.5^{\circ}$ and $4^{\circ} \times 5^{\circ}$ simulation, and between the $2^{\circ} \times 2.5^{\circ}$ and $1^{\circ} \times 1^{\circ}$ simulation.

[24] The difference between results obtained with the high- and low-resolution models, we shall show, reflects more efficient ventilation of the lower atmosphere in the former case as compared with the latter. The difference is small in the upper troposphere except when deep convection is actively involved in outflow, since horizontal transport is fast and tends to dilute accumulation of tracers rising from the lower troposphere. The difference in vertical ventilation occurs under circumstances for which there is a significant variation in vertical velocities (defined at a resolution of $1^{\circ} \times 1^{\circ}$ ) over a grid element of the low-resolution model. The mixing ratio of $\mathrm{CO}$ decreases rapidly with altitude as indicated in Figure 5. The flux of $\mathrm{CO}$ associated with upward advective motion is thus significantly greater than the flux associated with downward motion. Vertical advective transport of CO computed on the scale of the $4^{\circ} \times 5^{\circ}$ model using velocities averaged over the grid can differ therefore from the average of fluxes computed using the higher-resolution model. Suppose for example that the average velocity over a $4^{\circ} \times 5^{\circ}$ grid element is zero reflecting a balance of strong upward motion in part of the domain with compensating downward motion elsewhere. The net flux in the low-resolution model would be zero in this case while the net fluxes obtained with the higher-resolution model would be directed upward and could be significant resulting in important vertical redistribution of tracer.
[25] Conservation of tracer mass in the sigma coordinate system is expressed through the continuity equation [Holton, 1992; Seinfeld and Pandis, 1998]

$$
\frac{\partial C}{\partial t}+\nabla \cdot(C \mathbf{V})+\frac{\partial(C \dot{\sigma})}{\partial \sigma}=R+E-S,
$$

where $C$ denotes the tracer concentration, $\mathbf{V}$ represents the velocity along a particular sigma surface (components $u$ and $v$ in the zonal and meridional directions respectively) and $\dot{\sigma} \equiv D \sigma / D t$ defines the magnitude of the velocity normal to the sigma surface. The terms $R, E$, and $S$ on the right-hand side of (1) represent chemical generation, emission, and removal rate, respectively. The first term in the left-hand side of (1) denotes the mass tendency, the time rate of change of tracer mass at a particular location. The second
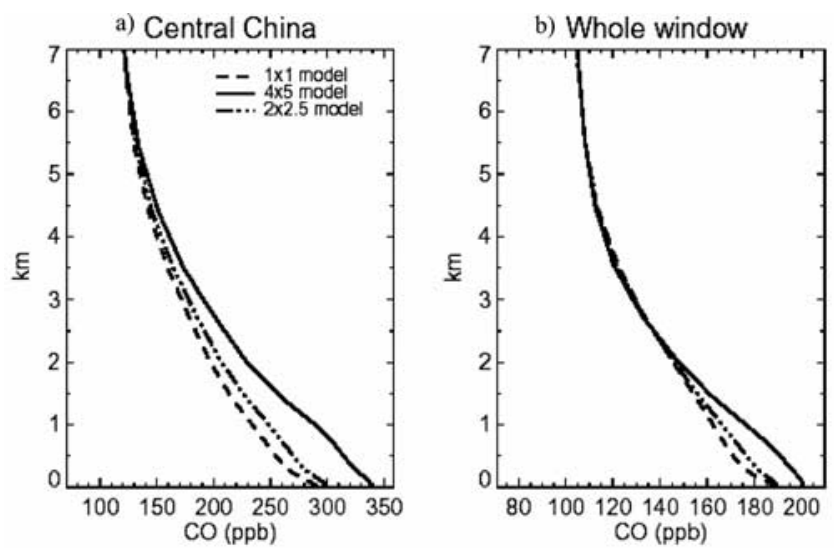

Figure 5. Vertical profiles of $\mathrm{CO}$ mixing ratios for (a) the central China region and for (b) the whole window region. The location of the central China region in Figure 5a is shown by the dashed white rectangle in Figure 4 . The dashed black line is for $1^{\circ} \times 1^{\circ}$-resolution nested model, the solid black line for the $4^{\circ} \times 5^{\circ}$-resolution global model, and the dashed-dotted line for the $2^{\circ} \times 2.5^{\circ}$ global model. 
expresses the change in mass on a sigma surface associated with motion along the surface while the third reflects the change in mass resulting from motion normal to the surface.

[26] The velocity normal to a sigma surface, defined by $\dot{\sigma} \equiv D \sigma / D t$, may be expressed in terms of the analogous quantity used to specify motion normal to a pressure surface, $\omega \equiv D p / D t(\mathrm{mb} / \mathrm{s})$, using the relationship [Holton, 1992]

$$
\dot{\sigma}=-\frac{\sigma}{p_{s}}\left(\frac{\partial p_{s}}{\partial t}+\mathbf{V} \cdot \nabla p_{s}\right)+\frac{\omega}{p_{s}} .
$$

[27] In turn, the true vertical velocity, $w(\mathrm{~m} / \mathrm{s})$, may be evaluated to an adequate approximation using the relation $\omega=-\rho g w$, where $\rho$ is the density of the air and $g$ denotes the acceleration of gravity. Note that negative values of $\omega$ correspond to regions of upward motion; downward motion is associated with conditions where $\omega$ is positive. The continuity equation in the pressure coordinates is:

$$
\frac{\partial C}{\partial t}+\nabla \cdot(C \mathbf{V})+\frac{\partial(C \omega)}{\partial p}=R+E-S
$$

To facilitate an intuitive understanding of the vertical motion, the discussion below is focused on equation (3) in the pressure coordinate, although the GEOS-CHEM model uses the sigma coordinate.

[28] Since the vertical resolution is the same in the global and nested model, the values of $\mathrm{X}$ on the coarse and highresolution grids can be represented by $\mathrm{X}(\mathrm{i})$ and $\mathrm{X}(\mathrm{i}, \mathrm{j})$ respectively $(j=1,20)$. Advection in the vertical direction across a particular $(i, j)$ element of the high-resolution grid should be proportional to the quantity $C(i, j) \omega(i, j)$. Averaging over $\mathrm{j}$ to evaluate the mass flux in the vertical direction appropriate for the $4^{\circ} \times 5^{\circ}$ representation for example, with obvious notation, we may write

$$
\frac{1}{20} \sum_{j=1}^{20} C(i, j) \omega(i, j)=\overline{C(i)} \overline{\omega(i)}+\frac{1}{20} \sum_{j=1}^{20} C^{\prime}(i, j) \omega^{\prime}(i, j),
$$

where $\overline{C(i)}=\frac{1}{20} \sum_{j=1}^{20} C(i, j)$ and $\overline{\omega(i)}=\frac{1}{20} \sum_{j=1}^{20} \omega(i, j)$. Hence $C^{\prime}(i, j)$ and $\omega^{\prime}(i, j)$ define the departures of $C(i, j)$ and $\omega(i, j)$ from the average values of these quantities over the corresponding $4^{\circ} \times 5^{\circ}$ grid: $C(i, j)=\overline{C(i)}+C^{\prime}(i, j)$, $\omega(i, j)=\overline{\omega(i)}+\omega^{\prime}(i, j)$, and $\sum_{j=1}^{20} C^{\prime}(i, j)=\sum_{j=1}^{20} \omega^{\prime}(i, j)=0$.

[29] In its customary formulation, the $4^{\circ} \times 5^{\circ}$ model assumes that

$$
\frac{1}{20} \sum_{j=1}^{20} C(i, j) \omega(i, j)=\overline{C(i)} \overline{\omega(i)}
$$

equivalent to an assertion that variations in $C(i, j)$ and $\omega(i, j)$ are uncorrelated over the domain spanned by j. For tracers such as $\mathrm{CO}$ which decrease with height over polluted regions, $C(i, j)$ and $\omega(i, j)$ are typically anticorrelated. That is, upward motions (negative $\omega$ ) are associated with higher concentrations of $\mathrm{CO}$ while downward motions (positive $\omega$ ) are associated with lower concentrations. Under circumstances for which there is a significant variation in vertical velocities (defined at a resolution of $1^{\circ} \times 1^{\circ}$ ) over a grid element of the low-resolution model, the assumption of equation (5) can lead to a significant underestimate in vertical ventilation of the lower atmosphere in the coarse global model. More generally, the comparison between equations (4) and (5) would suggest that differences between the coarse and fine-resolution models can be expected wherever tracers have strong horizontal gradients normal to the direction of motion being considered (e.g., zonal gradients lead to meridional transport where smallscale cyclonic or anticyclonic circulations occur). The underestimation of vertical ventilation is expected to decrease with increasing horizontal resolutions, as suggested by the comparisons between the three models shown in Figures 4 and 5, and could become insignificant when the model resolution is increased to the extent that much of the relevant information on large-scale advections is already contained.

[30] Time series for $\omega$ are presented for two specific $4^{\circ} \times$ $5^{\circ}$ grid elements in Figure 6 , one centered over central China $\left(30^{\circ} \mathrm{N}, 110^{\circ} \mathrm{E}\right)$, the other over the Yangtze River Delta $\left(30^{\circ} \mathrm{N}, 120^{\circ} \mathrm{E}\right)$. Results refer to an approximate altitude of $4 \mathrm{~km}$. Values of $\omega$ obtained by averaging results from the fine-resolution model (red line) are compared with the coarse-resolution simulation (black line). Values of $\dot{\sigma}$ would agree exactly for the two cases plotted this way. The figure includes also analogous information on vertical fluxes of CO. Note that fluxes are generally upward and typically larger in the case of the fine as compared to the coarse-resolution model. The differences reflect the importance of the nonlinearities noted earlier, the significance of localized regions of unusually intense upward motion. It is interesting to note the correlation between $\omega$ (top panel) and vertical fluxes of $\mathrm{CO}$ (bottom panel), which implies that synoptic features work in concert to produce different fluxes, rather than averaging out random/uncorrelated variations over larger scales.

[31] Differences are particularly large for 7 March. The meteorological conditions responsible for this condition are explored in more detail in Figure 7. The region of interest near $30^{\circ} \mathrm{N}$ was invaded by a cold front between 6 and 7 March. The position of the cold front, at an approximate altitude of $2 \mathrm{~km}$, is indicated by the thick red line in Figure 7a. Horizontal winds, represented by the black arrows, are generally from the north and west to the north of the front, from the south and west to the south. A region of strong upward motion is evident south of the front, with downward motion dominating to the north. The pattern is clearly captured by the high-resolution model but is less evident in the $4^{\circ} \times 5^{\circ}$ simulation (Figure $7 \mathrm{~b}$ ). Vertical fluxes of $\mathrm{CO}$ are much larger in the high-resolution simulation, especially to the immediate south of the front where transfer is predominantly directed upward. The spatial heterogeneity in the fluxes indicated in the $1^{\circ} \times 1^{\circ}$ model is also notably greater than that displayed in the low-resolution simulation.

[32] Overall budgets of $\mathrm{CO}$ for the region below $4 \mathrm{~km}$ as simulated by the high and low-resolution models are summarized in Table 1 . The Table clearly attests to the importance of vertical transfer both for the entire window domain and for the region over central China indicated by the white rectangles in Figure 4. As expected, fluxes of $\mathrm{CO}$ are directed generally upward and are notably larger with the $1^{\circ} \times 1^{\circ}$ as compared to the $4^{\circ} \times 5^{\circ}$ model. Vertical transport is associated both with net 
(a) Mar1-31 Omega at 4km Central China

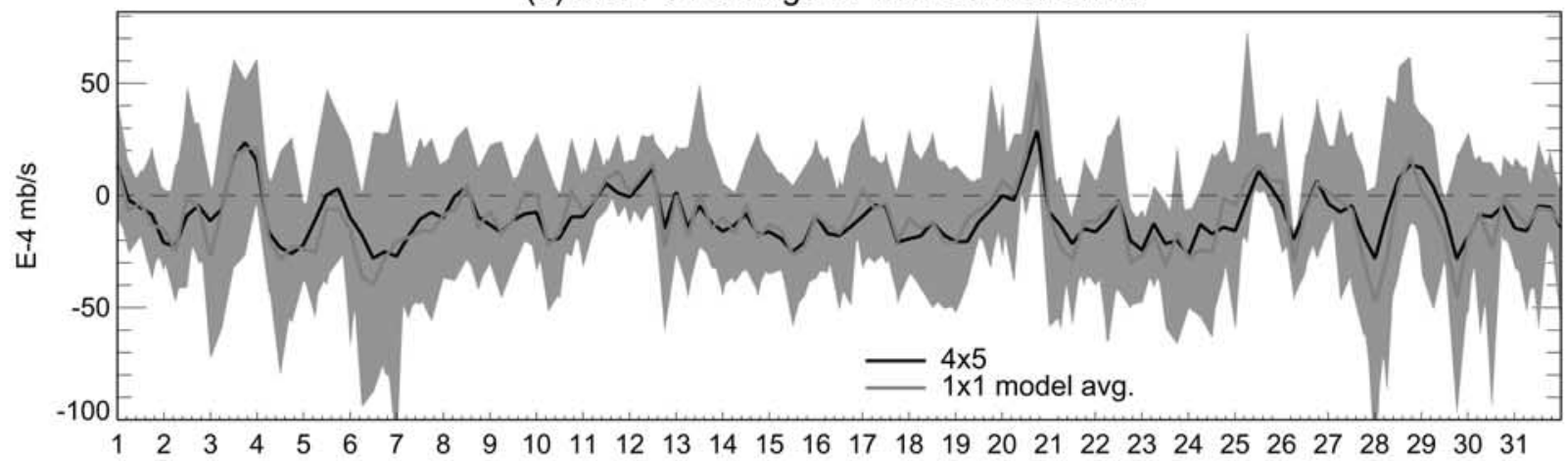

Mar1-31 Vertical CO flux at $4 \mathrm{~km}$ Central China

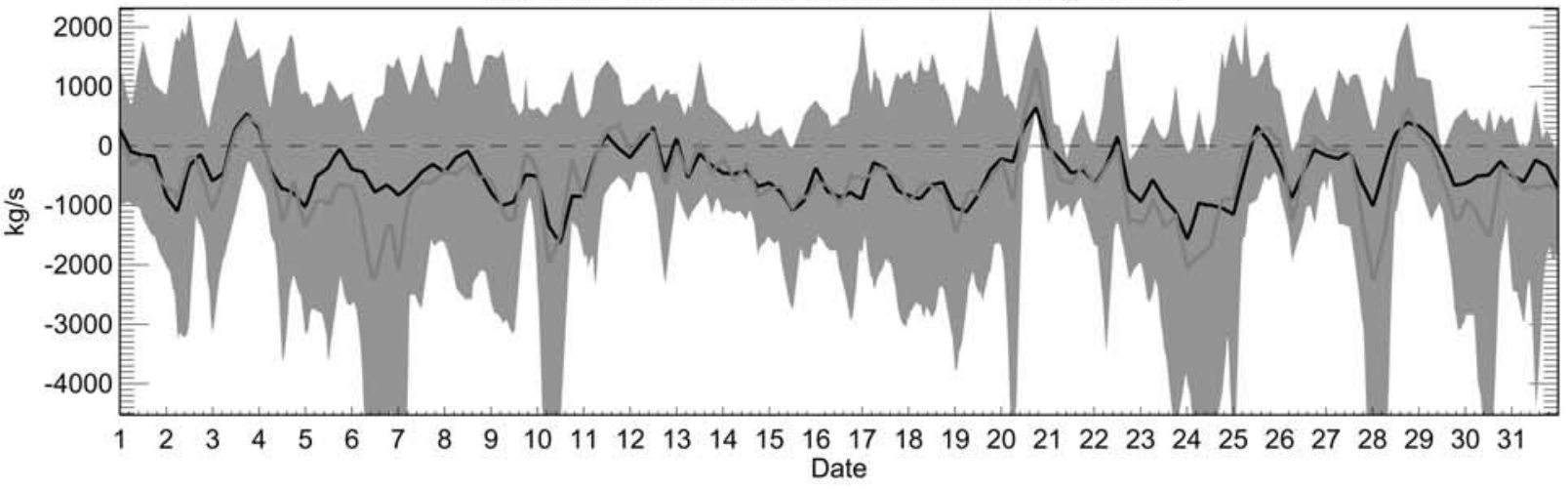

(b) Mar1-31 Omega at 4km YRD

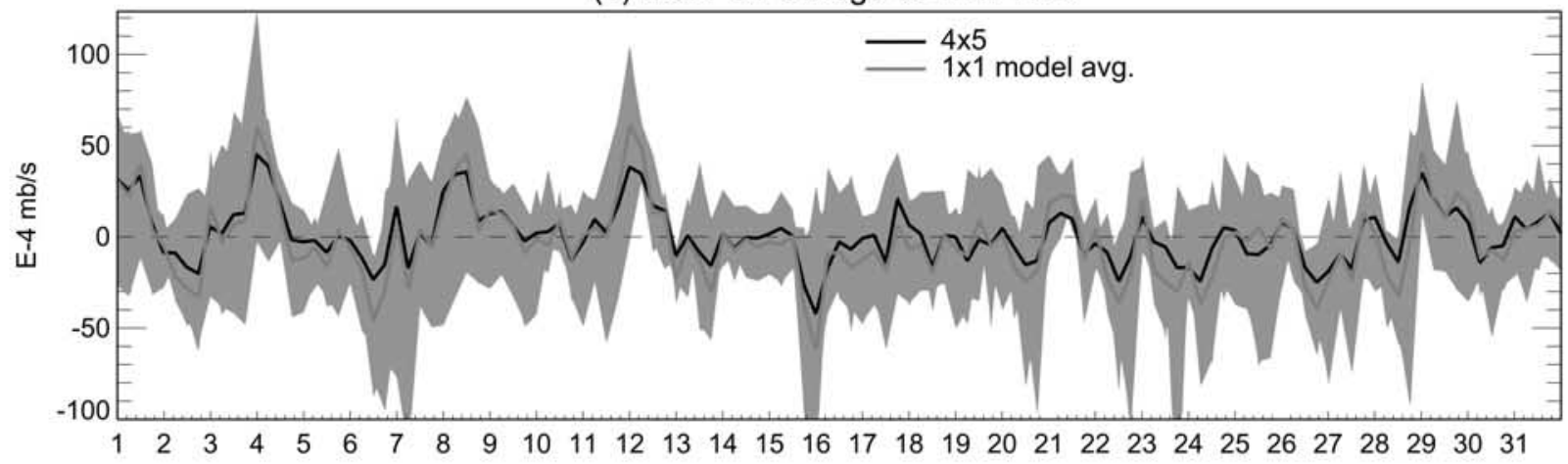

Mar1-31 Vertical CO flux at 4km YRD

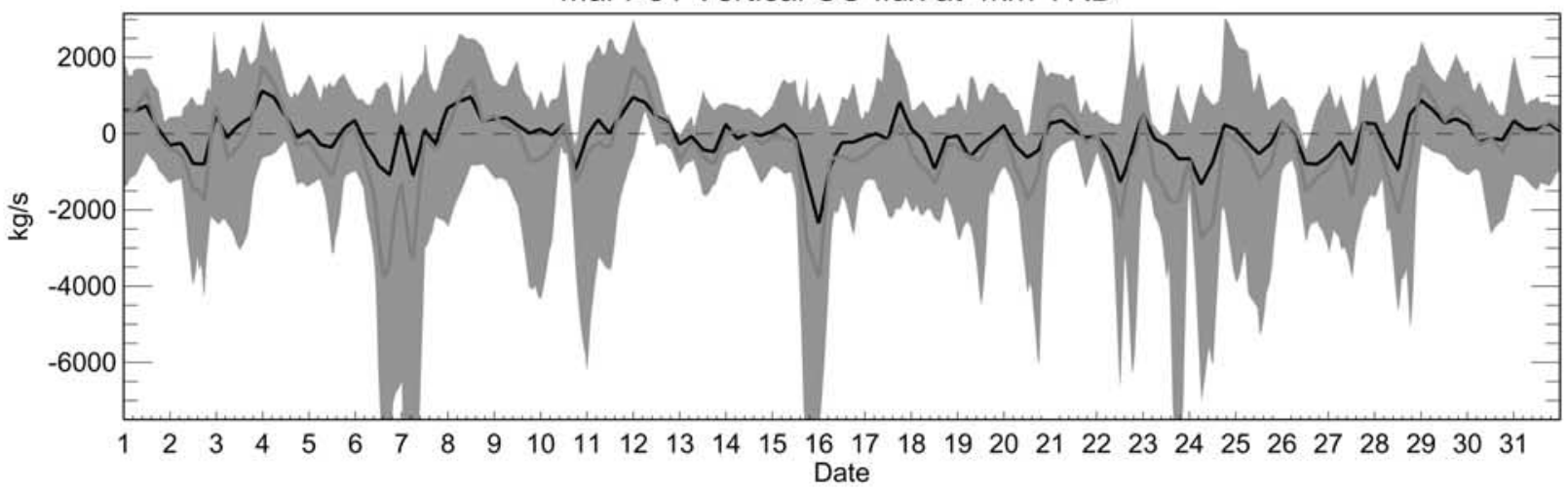

Figure 6 


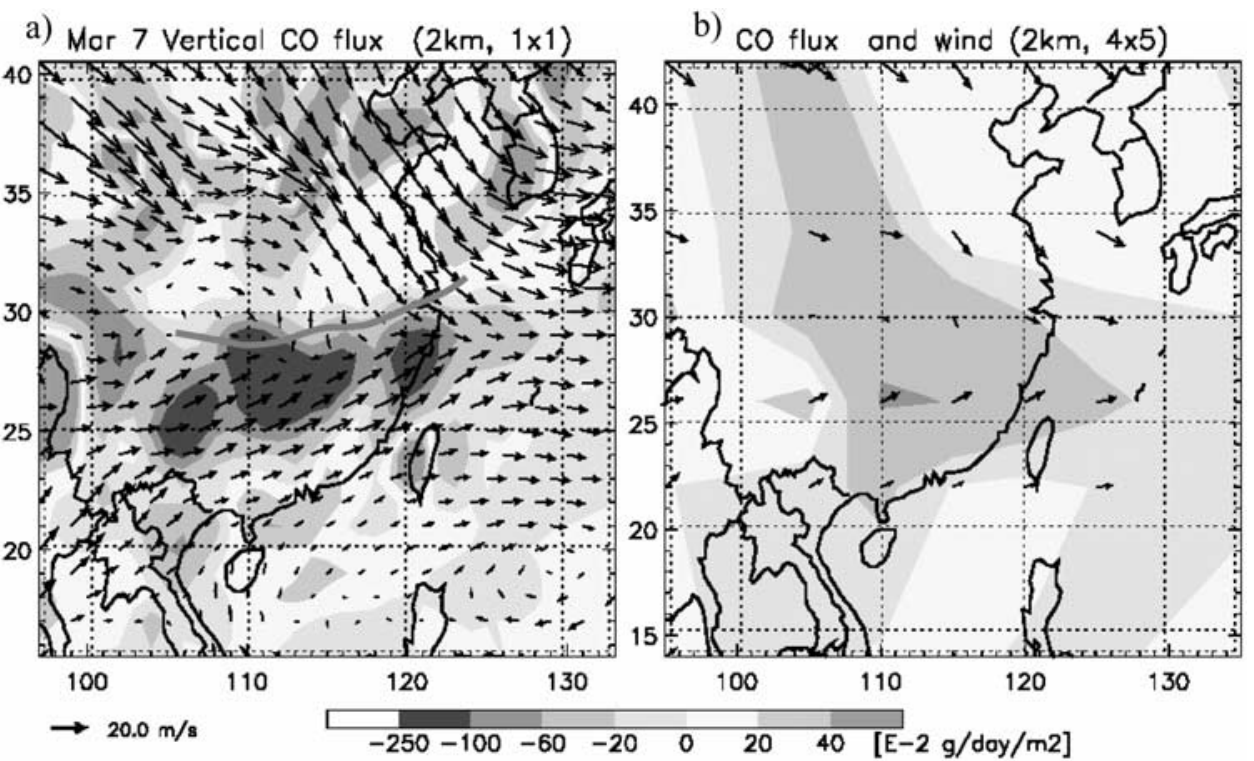

Figure 7. Wind vectors (black arrows) and vertical CO fluxes (color coding; unit: $\mathrm{gCO} / \mathrm{day} / \mathrm{m}^{2}$ ) at $2 \mathrm{~km}$ over the central China region for 7 March 2001, as calculated by (a) the high-resolution model and (b) the coarse-resolution model. Negative flux refers to upward motion and positive flux refers to downward motion. The thick red line in Figure 7a indicates the approximate location of a cold front at $2 \mathrm{~km}$. See color version of this figure at back of this issue.

motion of air and with convection, with the latter significant mainly over portions of India and southeast Asia. Horizontal advection contributes a net source of $\mathrm{CO}$ both to the entire window domain and to the region over central China. The source is significantly greater with the higher-resolution simulation. $\mathrm{CO}$ is imported horizontally to the window domain mainly through the northern boundary, indicating long range transport of $\mathrm{CO}$ from Europe to Asia. Transfer to altitudes above $4 \mathrm{~km}$ provides the major sink for $\mathrm{CO}$ in both models. The net chemical loss of CO amount to about $20 \sim 30 \%$ of the net loss due to transport. Reflecting the enhanced efficiency of vertical motion in the high-resolution model, the residence time for $\mathrm{CO}$ in the region below $4 \mathrm{~km}$ is somewhat less in this case and mean concentrations are reduced accordingly.

[33] Other factors that could contribute to differences in vertical ventilation between the different models include: (1) correlations between emissions and vertical velocity; (2) differences in boundary layer turbulence that provide for additional vertical diffusion below $2 \mathrm{~km}$; and (3) interactions between vertical advection and boundary layer turbulence. These factors are examined one by one in the fine-resolution model for the central China region (Figure 8). We found no correlation between emissions and vertical velocity $(\mathrm{R}=-0.02$; Figure $8 \mathrm{a})$. Boundary layer turbulence is treated in both models as a rapid and complete vertical mixing within the GEOS-diagnosed mixed layer. The mixing layer depth in the coarseresolution grid is an area-weighted average of that in the fine-resolution grid. A weak negative correlation was found between the mixing depth and emission rate in the fine-resolution model (Figure 8b; $\mathrm{R}=-0.33$ ), reflecting the tendency of high emission rates along coastal regions where mixing layers are relatively shallower than inland in springtime. Averaging out this negative correlation by the coarse-resolution model, if significant, would imply a more efficient vertical diffusion introduced by boundary layer turbulence in the coarse-resolution model than in the low-resolution model, which in turn would tend to reduce the underestimation of upward $\mathrm{CO}$ fluxes at the coarse resolution. Upward $\mathrm{CO}$ fluxes associated with boundary layer turbulence for the central China region, however, is found to be only $5 \%$ higher in the coarseresolution model than those in the fine-resolution model, as compared to a difference of $25 \%$ in advective vertical fluxes. The influence of boundary layer mixing is largely limited to altitudes below $2 \mathrm{~km}$, but could be extended to higher altitudes if correlated with vertical advection. Inspection of the fine-resolution model fields indicates an absence of such a correlation for the central China region $(\mathrm{R}=-0.14$; Figure $8 \mathrm{c})$.

[34] A major advantage of the nested grid model over regional models is the adoption of time-varying boundary conditions provided by a consistent global simulation. The

Figure 6. (a) Time series of vertical velocity $\omega$ (upper), and vertical CO fluxes (lower) at $4 \mathrm{~km}$ for one $4^{\circ} \times 5^{\circ}$ grid element centered at $\left(30^{\circ} \mathrm{N}, 110^{\circ} \mathrm{E}\right)$ in the central China region. The thick black line depicts results from the coarseresolution global model. Values obtained by averaging results from the fine-resolution nested model are indicated by the red line. The gray shaded area indicates the range of results from the high-resolution model prior to spatial averaging. (b) The same as Figure $6 \mathrm{a}$, but for a $4^{\circ} \times 5^{\circ}$ grid element centered at $\left(30^{\circ} \mathrm{N}, 120^{\circ} \mathrm{E}\right)$ in Yangtze River Delta (YRD) region. See color version of this figure at back of this issue. 
Table 1. Budget for CO Below $4 \mathrm{~km}$ for the Whole Window Region and for the Central China Region ${ }^{\mathrm{a}}$

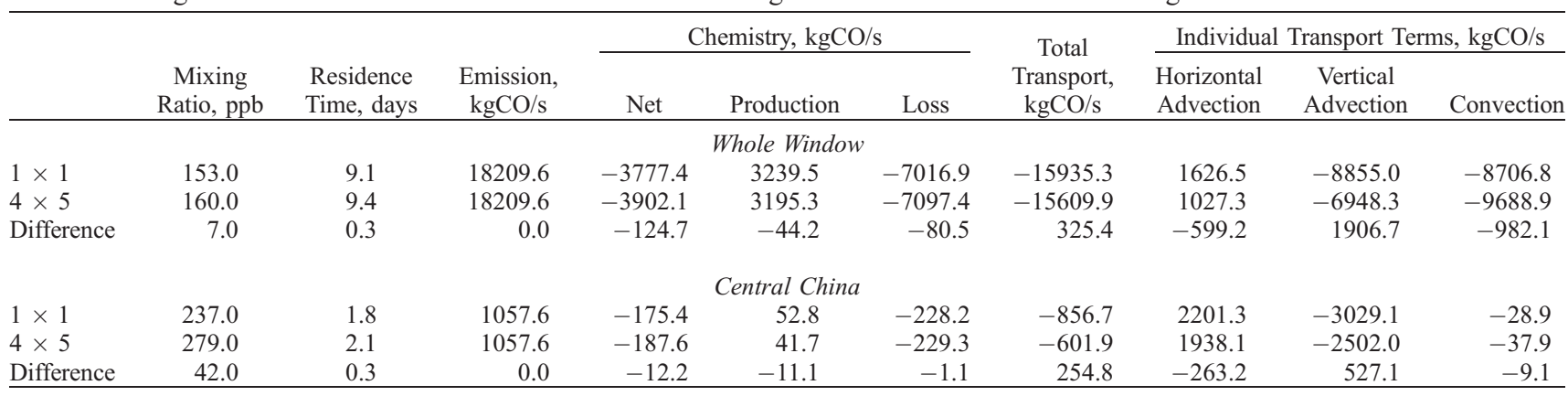

${ }^{\mathrm{a}}$ The data in the table are mean model values for March 2001. The location of the central China region is shown by the white rectangle in Figure 4. The differences are expressed as (coarse model - fine model). For budget terms, negative numbers indicate removal of CO (such as vertical and horizontal export) and positive numbers indicate addition of $\mathrm{CO}$ (such as emission).

influence of time-varying boundary conditions was assessed by examining the ratio of imported $\mathrm{CO}$ to internally emitted $\mathrm{CO}$ for the nested domain (Figure 9). Chemically produced CO (i.e., from oxidation of methane, isoprene, and other VOCs) was excluded in both terms. Figure 9 presents the averaged percentage ratio below $2 \mathrm{~km}$ for the first half (9a) and second half (9b) of March 2001. Imported CO contributes more than $30 \%$ of internally emitted $\mathrm{CO}$ for window regions north of $30^{\circ} \mathrm{N}$ and over the ocean, while the contribution decreases to about $10 \%$ for highly polluted regions in east India and southeast Asia. Imported CO has an obviously nontrivial impact on polluted regions in south and east China (south of $30^{\circ} \mathrm{N}$ and east of $110^{\circ} \mathrm{N}$ ), where it was responsible for about $30 \%$ of internal $\mathrm{CO}$ for the first half of March with a slightly decreased contribution for the second half of March. Figure 9 clearly attests to the importance of accurate and time-varying boundary conditions for the chemical transport of $\mathrm{CO}$ in the nested domain, despite the polluted nature of the region.

\section{Comparison With TRACE-P Observations}

[35] Data from the Transport and Chemical Evolution over the Pacific (TRACE-P) mission conducted over the period March-April 2001 provide a useful opportunity to test the ability of the nested grid model to simulate the outflow of CO from Asia. The mission sampled a wide range of locations over the western Pacific [Jacob et al., 2003]. We restrict attention here to analysis of results for the region west of $140^{\circ} \mathrm{E}$. To facilitate comparison of model and observation, outputs of the model were sampled along flight tracks for the specific times of the 22 flights involved in TRACE-P. The observational data were averaged over 1-min intervals and will be compared here with 1-hour averages of model output.

[36] An overall summary of results is presented in Figure 10. The data are displayed as functions of latitude. The observational results are indicated by vertical red lines denoting means and $1-\sigma$ standard deviations. Model output is presented in terms of means evaluated for specific flight times and conditions. The separate panels of the figure aggregate data from altitude intervals $0-2 \mathrm{~km}, 2-4 \mathrm{~km}$ and for the region above $4 \mathrm{~km}$. Agreement between model and observation is generally satisfactory. The higher-resolution model fares better than the low-resolution model in capturing the variability of concentrations implied by the observations. This is particularly true for the boundary layer and for the region north of $20^{\circ} \mathrm{N}$. The fine-resolution model is (a) Emiss. vs. omega, Central China

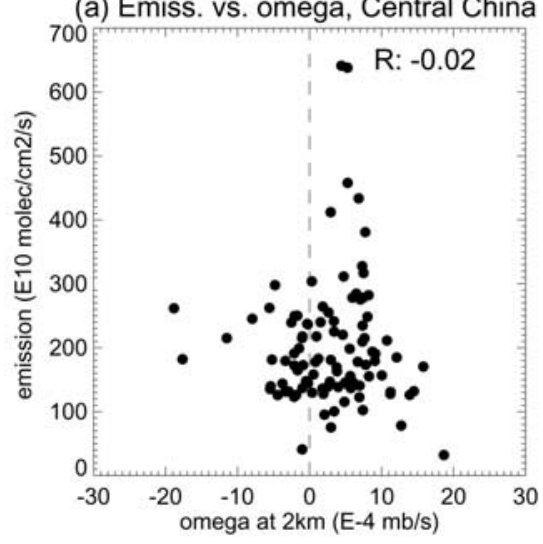

(b) Emiss. vs. PBL, Central China

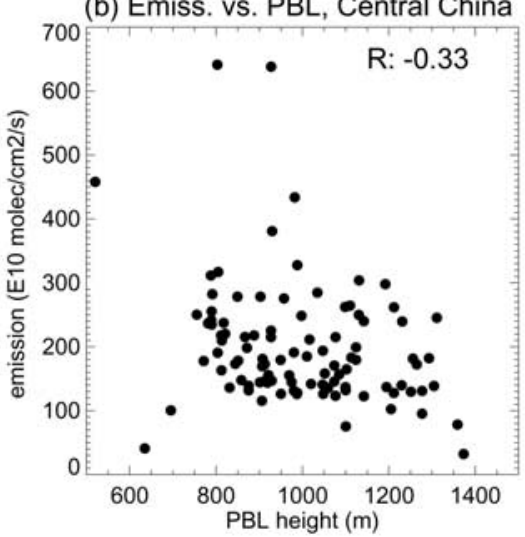

(c) PBL vs. omega, Central China

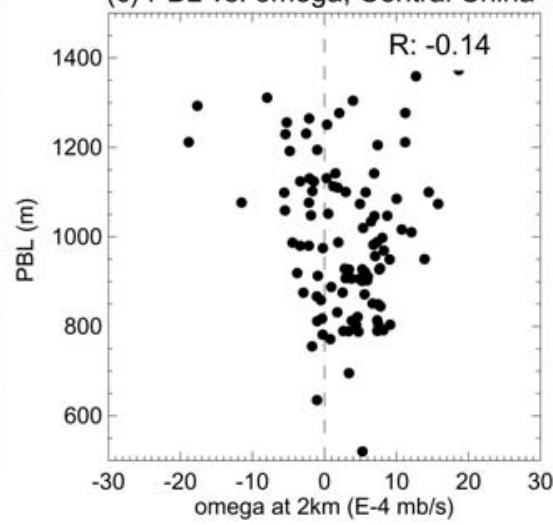

Figure 8. Scatterplot of (a) emission rate versus omega, (b) emission rate versus afternoon maximum planetary boundary layer (PBL) height, and (c) PBL height versus vertical velocity (omega) for the central China region (highlighted by the dashed white rectangle in Figure 4). The data displayed refer to averages for March 2001 in the fine-resolution model. Correlation coefficients are also shown. 
(a) Mar1-15 imported/internal CO (\%; 0-2km)

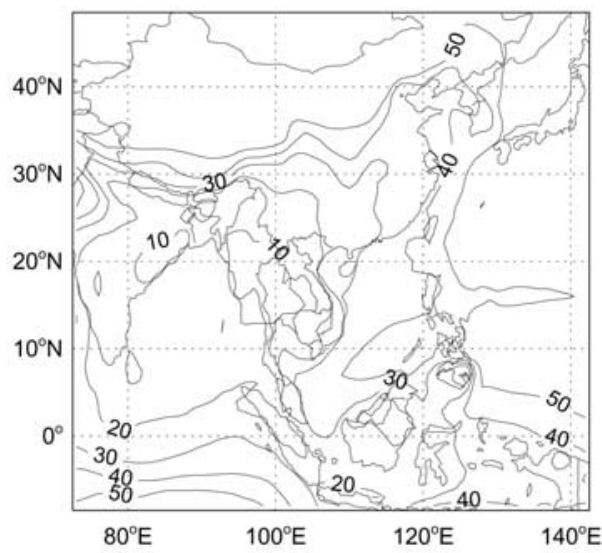

(b) Mar16-31 imported/internal CO (\%; 0-2km)

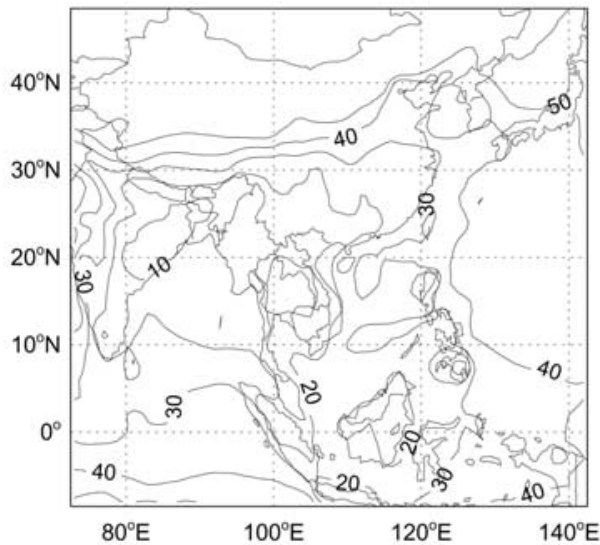

Figure 9. Averaged percentage ratio of imported $\mathrm{CO}$ to internally emitted $\mathrm{CO}$ below $2 \mathrm{~km}$ for (a) the first half and (b) the second half of March 2001. Chemically produced CO is excluded in the calculation. Contour levels are: $10 \%, 20 \%, 30 \%, 40 \%$, and $50 \%$.

more successful also in accounting for the higher concentrations observed in polluted air masses. Concentrations predicted for the boundary layer using the fine-resolution model are generally lower than those obtained with the course-resolution model, especially for latitudes greater than about $20^{\circ} \mathrm{N}$. The difference in this case may be attributed to more efficient ventilation of the boundary layer in the fineresolution model as discussed earlier.

[37] Analysis of the correlation between model and observational data offers an alternative approach to assess the quality of models. Figure 11 presents a summary of correlation coefficients $(\mathrm{R})$ evaluated by comparing model results with the totality of the observational data for each of the individual flights. Values of $\mathrm{R}$ in the upper panel of
Figure 11 were calculated using grid-size averaged observations and model predictions ( $\mathrm{R}$ values on the model scale). That is, the high-resolution model is evaluated using observations with higher spatial variance (on a scale of $1^{\circ} \times 1^{\circ}$ ), while the coarse-resolution model is evaluated using observations with lower spatial variance (on a scale of $4^{\circ} \times 5^{\circ}$ ). Values of R in the lower panel of Figure 11 were calculated on a point by point basis between observations and model predictions ( $\mathrm{R}$ values on the observation scale). With few exceptions in either method of calculating $\mathrm{R}$, the correlation between model and observation obtained with the higherresolution formulation is superior. In most cases $\mathrm{R}$ is greater than 0.6 , in several instances approaching 0.9 with an average of 0.75 (model scale) and 0.72 (observation scale). This may (a) $0-2 \mathrm{~km}$

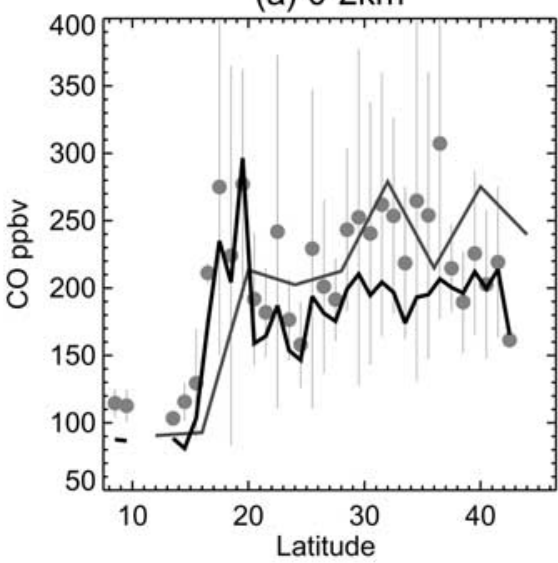

(b) $2-4 \mathrm{~km}$

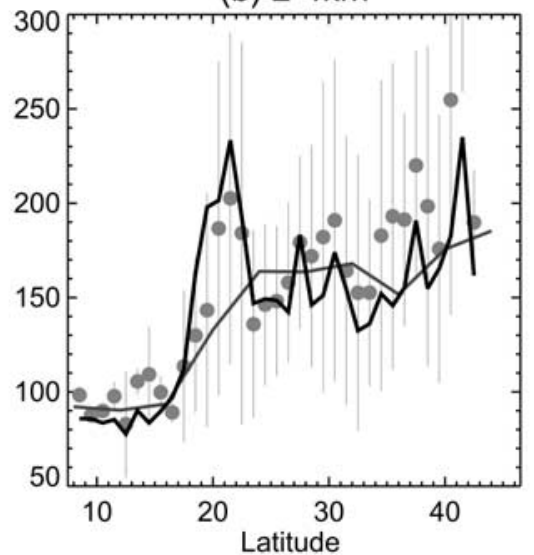

(c) $>4 \mathrm{~km}$

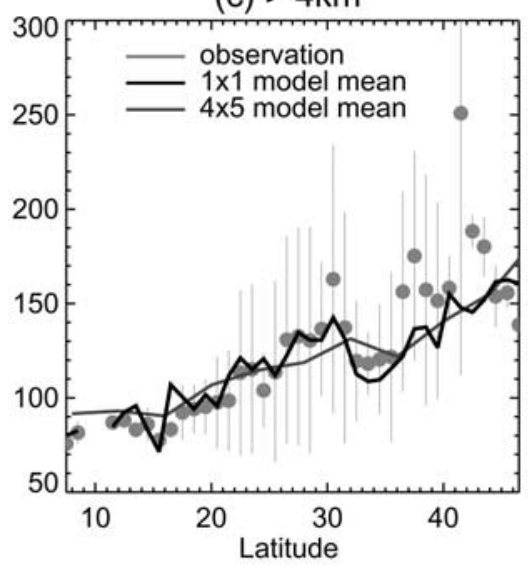

Figure 10. Latitudinal distribution of measured and modeled CO during TRACE-P. Data are shown for three altitude ranges of (a) $0-2 \mathrm{~km}$, (b) $2-4 \mathrm{~km}$, and (c) $>4 \mathrm{~km}$. For each altitudinal range, observations are averaged over $1^{\circ}$ latitudinal bins. Red dots denote the mean observed values and red vertical bars denote $1-\sigma$ values about the mean. The mean values of the high-resolution $\left(1^{\circ} \times 1^{\circ}\right)$ model results are shown by the black line. Those of the coarse-resolution $\left(4^{\circ} \times 5^{\circ}\right)$ model results are shown in blue. See color version of this figure at back of this issue. 

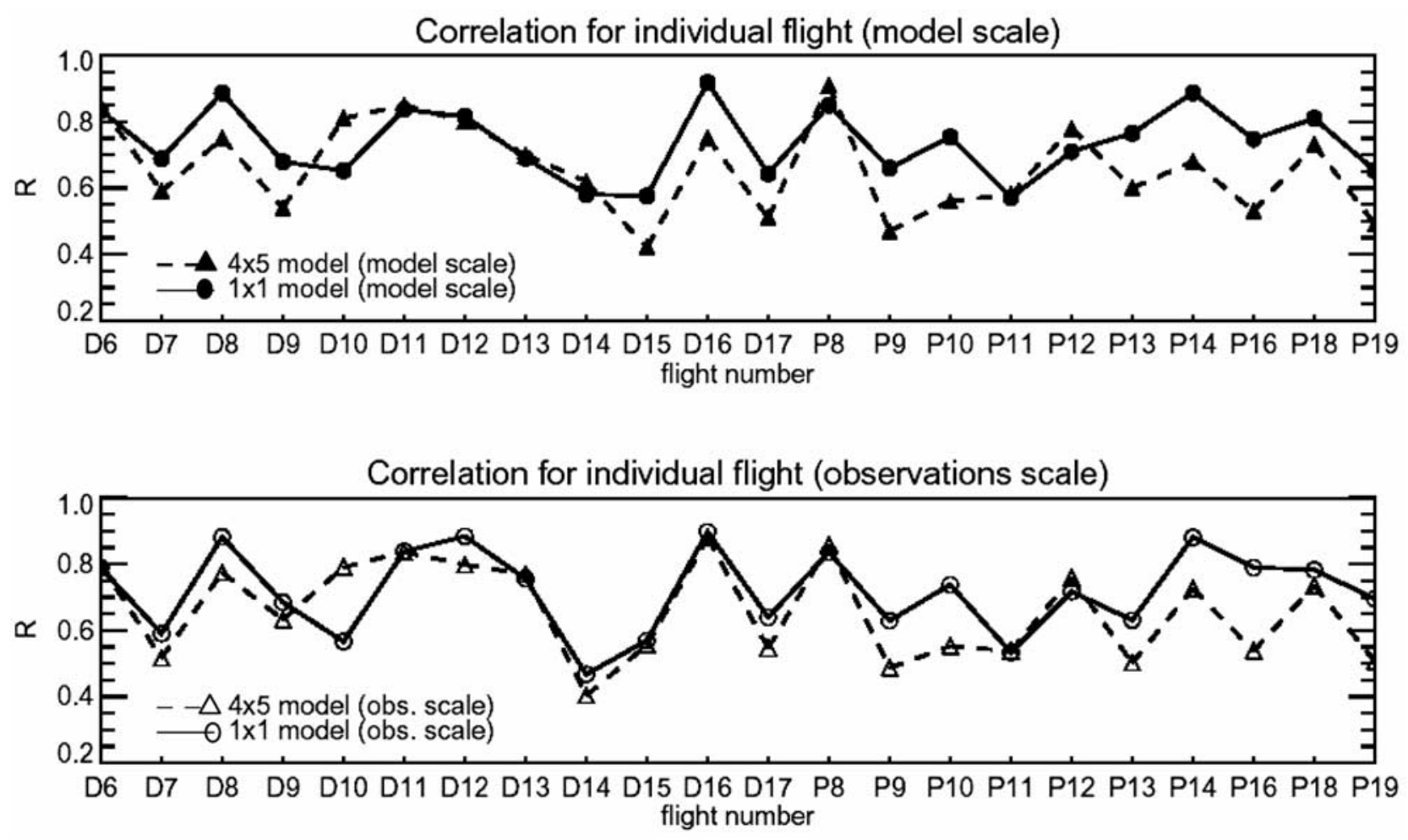

Figure 11. Correlation coefficients $(\mathrm{R})$ for modeled $\mathrm{CO}$ versus observed $\mathrm{CO}$ for individual flights in the TRACE-P mission. $\mathrm{R}$ values in the upper panel are calculated using grid-size averaged observations and model predictions ( $\mathrm{R}$ values on the model scale). $\mathrm{R}$ values in the lower panel are calculated on a point by point basis between observations and model predictions ( $\mathrm{R}$ values on the observation scale). The $\mathrm{D}$ label on the $x$ axis indicates DC-8 flights, and the P label indicates P3-B flights. P3B flight numbers 15 and 17 are not included because they mainly sampled regions outside the nested domain (east of $140^{\circ} \mathrm{E}$ ).

be compared with the average of 0.66 (model scale) and 0.64 (observation scale) obtained using the coarse-resolution model. Kiley et al. [2003] compared model-derived CO obtained from seven CTMs (four global models and three regional models) with $\mathrm{CO}$ observations made on the DC-8 flights during the TRACE-P campaign and reported a typical correlation of between 0.55 and 0.65 on the model scale. They found no significant difference between regional and global models. This may be attributed partly by the fact that models at different resolutions are evaluated against observations with spatial variances corresponding to the model grid size. On the other hand, the regional and global models involved in their study differ not only in resolution, but in the treatment of transport and meteorological fields used to drive the CTMs. Lawrence et al. [2003] compared model predicted CO obtained from a global chemical forecast system with three field campaigns and found an typical correlation of greater than 0.7 on the observation scale, similar to that indicated in Figure 11.

[38] We turn our attention now to analysis of results from individual flights. A specific objective will be to relate contributions from different source regions to concentrations observed at particular locations along particular flight tracks. To this purpose, we label emissions from ten distinct regions, Japan and Korea, southeast Asia, India, western China, northeastern China, northern China, central China, central south China, southeast China, and the rest of the world, as indicated in Figure 12. The high-resolution window approach allows us to differentiate contributions from individual subregions of China on a much finer scale than was possible previously [Bey et al., 2001b; Liu et al., 2003]. The influence of the rest of the world is incorporated in the present formulation through its impact on the time varying boundary conditions imposed on the window region using results from the lower-resolution global model. Secondary sources of $\mathrm{CO}$ associated with oxidation of volatile organic carbon (VOC) species such as $\mathrm{CH}_{4}$ and isoprene were evaluated previously with the global GEOS-CHEM model (B. Duncan, Model study of the variability and trends of carbon monoxide (1988-1997) 1. Model formulation, evaluation, and sensitivity, submitted to Journal of Geophysical Research, 2004) and are included here for convenience under the category "rest of the world". We begin with a discussion of results from the 7 March DC-8 flight (flight number D7 in Figure 11).

[39] As noted earlier, a strong cold-surge event occurred on 7 March 2001. Surface wind patterns from the GEOS-3 data, reproduced in Figure 13a, indicate the presence of a high pressure system over east China (the influence of the Siberia High) with a region of low pressure to the northeast of Japan (a transient middle latitude low; see Fuelberg et al. [2003]). Pressure gradients associated with these features are responsible for the outbreak of cold air observed on this occasion extending from the northwest to the east and south. 


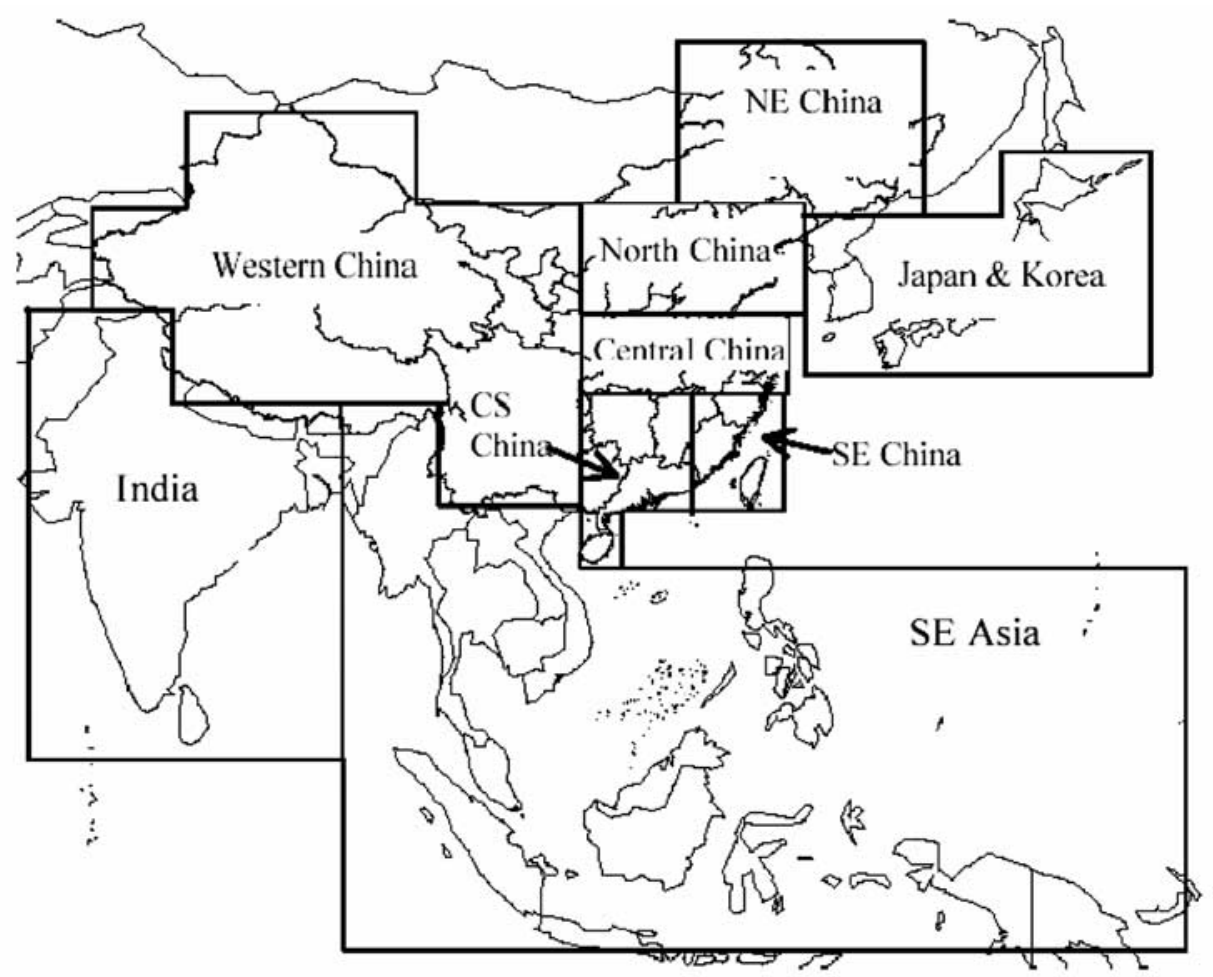

Figure 12. Source regions for tagged $\mathrm{CO}$ simulation.

As the leading edge of the cold surge advanced toward the east and South China Sea on 7 March, it was delineated at the surface by a cold front extending from south China to the north of Japan [Liu et al., 2003]. The approximate location of this front is indicated by the thick black line in Figure 13a. The different positions of the fronts marked on Figures $7 \mathrm{a}$ and $13 \mathrm{a}$ reflect mainly differences in altitude. The meteorological setting for 7 March defined by the GEOS-3 data matches the general description of cold-surge events reported in the literature [Lau and Li, 1984; Zhang et al., 1997]. Lau and $L i$ [1984], for example, suggest that passages of upper level troughs at midlatitudes are responsible for cyclogenesis over Japan and anticyclogenesis over east China. Cold surges arise as a consequence of the intervening pressure gradient.

[40] TRACE-P DC-8 flight D7 originated in Hong Kong on 7 March. The flight track, depicted in Figure 13a, was initially to the southeast, turning to the east at latitude $20^{\circ} \mathrm{N}$, then to the northeast at longitude $120^{\circ} \mathrm{E}$. The aircraft encountered the cold front first at a latitude of about $25^{\circ} \mathrm{N}$ and subsequently at about $31^{\circ} \mathrm{N}$ as the fight track shifted east extending to a longitude of about $140^{\circ} \mathrm{E}$ before returning on a southwest and finally westward track back to base in Hong Kong. Elevated concentrations of $\mathrm{CO}$, attributed to frontal lifting, were observed ahead of the cold front on both the first and second encounters and also behind the front on the second encounter. Concentrations in excess of $300 \mathrm{ppb}$ were measured at altitudes between 5 and $8 \mathrm{~km}$ as the aircraft passed by the front at $31^{\circ} \mathrm{N}$ (Figure 13b, part B and C). Lifting ahead of the cold front is captured by both the fine and coarse-resolution models (Figures $13 \mathrm{~b}$ and 13c, part $\mathrm{A}, \mathrm{B}$, and $\mathrm{C}$ ) but the agreement with observation is notably better with the higher-resolution model. The obser- vations indicate lifting to altitudes between 5 and $8 \mathrm{~km}$ with concentrations of $\mathrm{CO}$ as high as $340 \mathrm{ppb}$. Lifting in the fineresolution model reaches to between 5 and $7 \mathrm{~km}$ with concentrations as high as about $300 \mathrm{ppb}$ (Figure 13b, part $\mathrm{C}$ ). In contrast, lifting in the coarse-resolution model is much less efficient extending only to about $5 \mathrm{~km}$ with concentrations of CO peaking at about $250 \mathrm{ppb}$ (Figure 13c, part C). An earlier analysis of the data from this flight by Liu et al. [2003] using a $2^{\circ} \times 2.5^{\circ}$ version of GEOS-CHEM model simulated lifting and concentrations intermediate between results obtained here using the coarse $\left(4^{\circ} \times 5^{\circ}\right)$ and fine $\left(1^{\circ} \times 1^{\circ}\right)$ resolution models.

[41] Contributions to model derived concentrations of $\mathrm{CO}$ attributable to emissions originating in China and southeast Asia are indicated in Figure 13d. Results displayed here, obtained using the high-resolution model, suggest that emissions from southeast Asia provide the dominant source of $\mathrm{CO}$ for the free troposphere south of $30^{\circ} \mathrm{N}$. The model tends to overestimate concentrations of $\mathrm{CO}$ in this region (see also panels b and c of Figure 10), supporting conclusions reached earlier by Heald et al. [2003] and Palmer et al. [2003] that emissions estimated for southeast Asia may be too high. The model tends to underestimate concentrations of $\mathrm{CO}$ observed in the free troposphere $(5-8 \mathrm{~km})$ in the frontal outflow region sampled near $30^{\circ} \mathrm{N}$ (Figures $13 \mathrm{~b}$ and $13 \mathrm{c}$, part $\mathrm{B}$ and $\mathrm{C})$. Tagged simulation studies indicate that the dominant contribution (above background) to $\mathrm{CO}$ observed in this region should originate from China south of $32^{\circ} \mathrm{N}$. The model appears also to underestimate concentrations of $\mathrm{CO}$ for the boundary layer north $20^{\circ} \mathrm{N}$ (see also Figure 10a) where, again, emissions from China are expected to dominate. The discrepancies between model and observa- 
a) DC8 Flight $\$ 7$ co obs. and surface winds

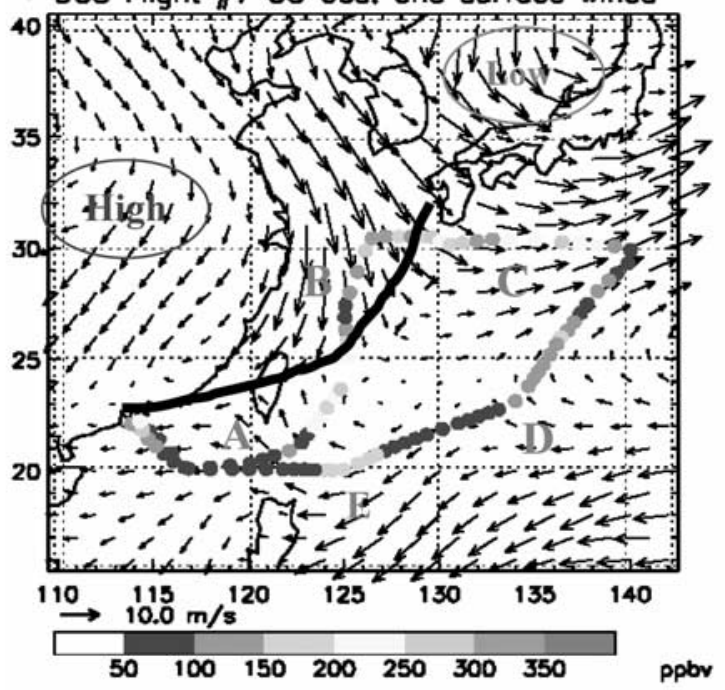

(b) TRACEP DC8-7 and $1 \times 1$ Model

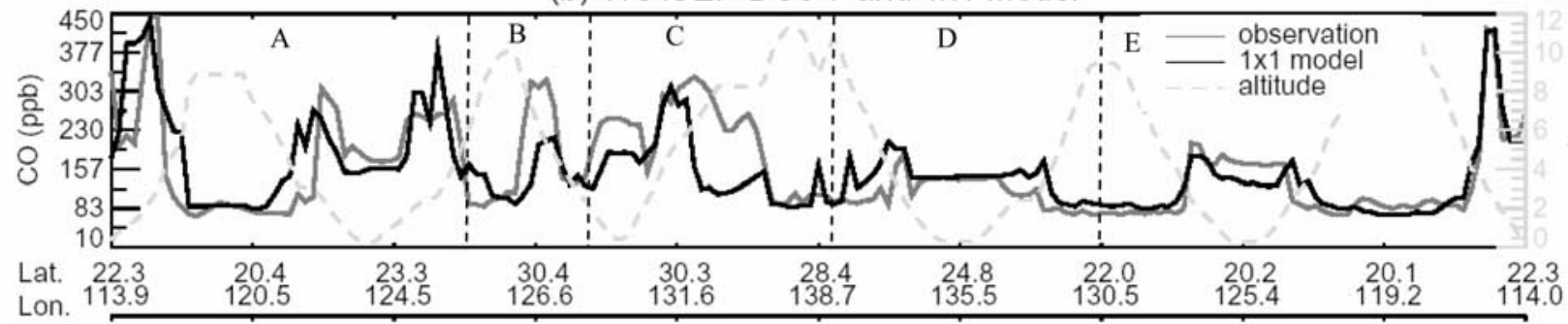

(c) TRACEP DC8-7 and 4x5 Model

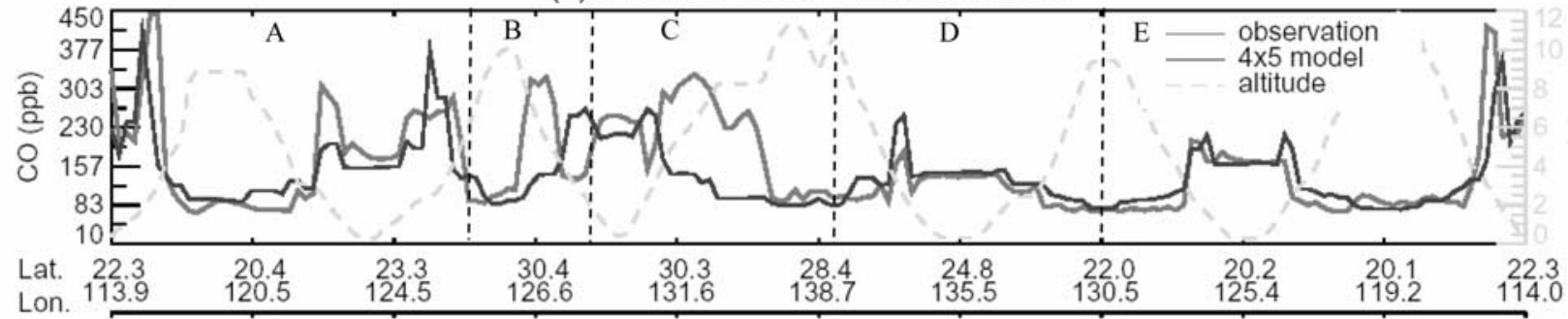

(d) Contributions from tagged tracers

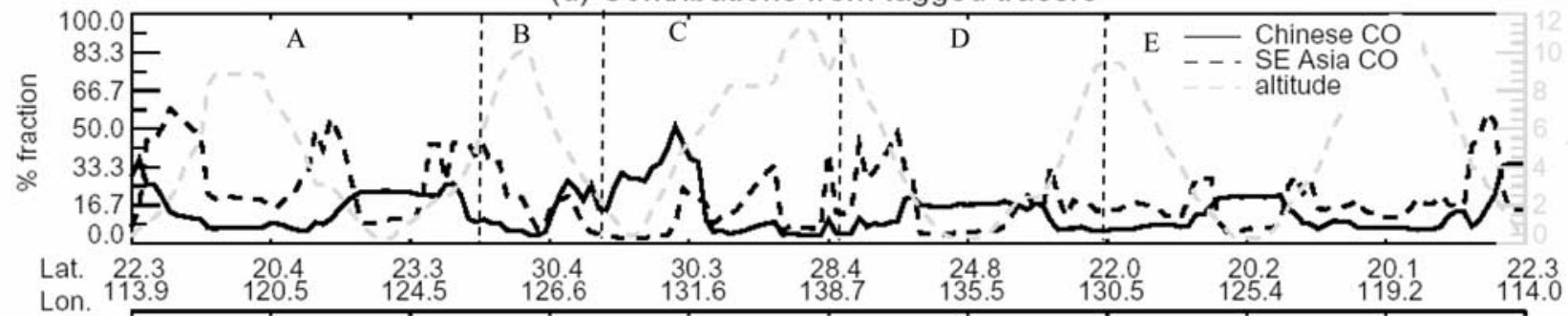

Figure 13. (a) Flight track (colored line) of DC-8 flight 7 during TRACE-P and surface wind vectors on 7 March 2001. The colors indicate CO mixing ratios observed along the flight track. Direction changes of this flight are marked by $\mathrm{A} / \mathrm{B} / \mathrm{C} / \mathrm{D} / \mathrm{E}$. The thick black line shows the approximate location of a surface cold front. (b) CO observations made by DC-8 flight 7 (red line) and CO concentrations simulated by the high-resolution model (black line) along flight track on 7 March 2001. Flight altitude is shown by the dashed green line. The $x$ axis is time but labeled in latitude and longitude along the flight track. Flight direction changes are indicated by $\mathrm{A} / \mathrm{B} / \mathrm{C} / \mathrm{D} / \mathrm{E}$ corresponding to Figure 13a. (c) The same as Figure 13b, but for CO simulated by the coarse-resolution model (blue line). (d) Simulated percentage contributions from Chinese CO sources (solid black line) and southeast Asian CO sources (dashed black line) along the flight track. See color version of this figure at back of this issue. 


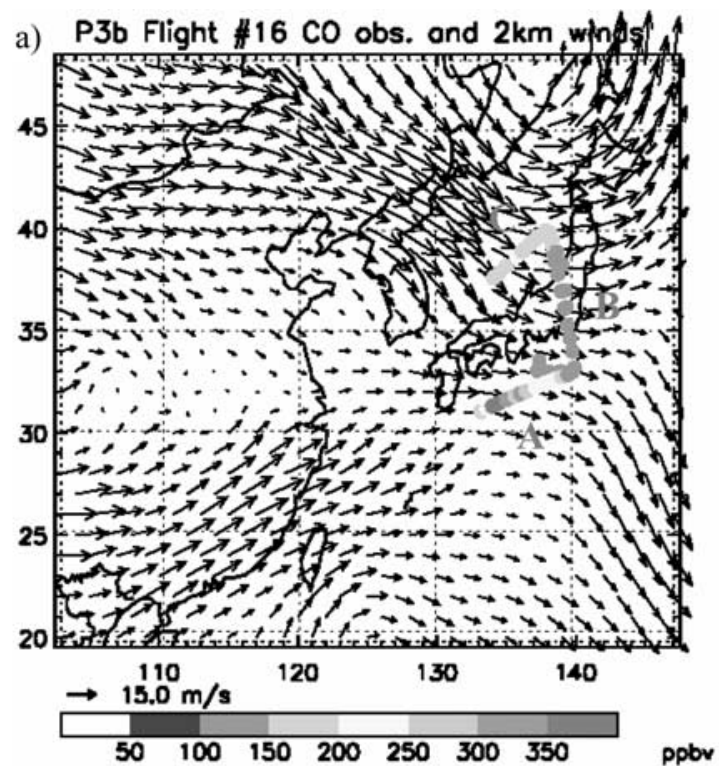

(b) Mar 23 Omega and wind $(2 \mathrm{~km}, 1 \times 1)$

(c) Mar 23 Omega and wind $(2 \mathrm{~km}, 4 \times 5)$

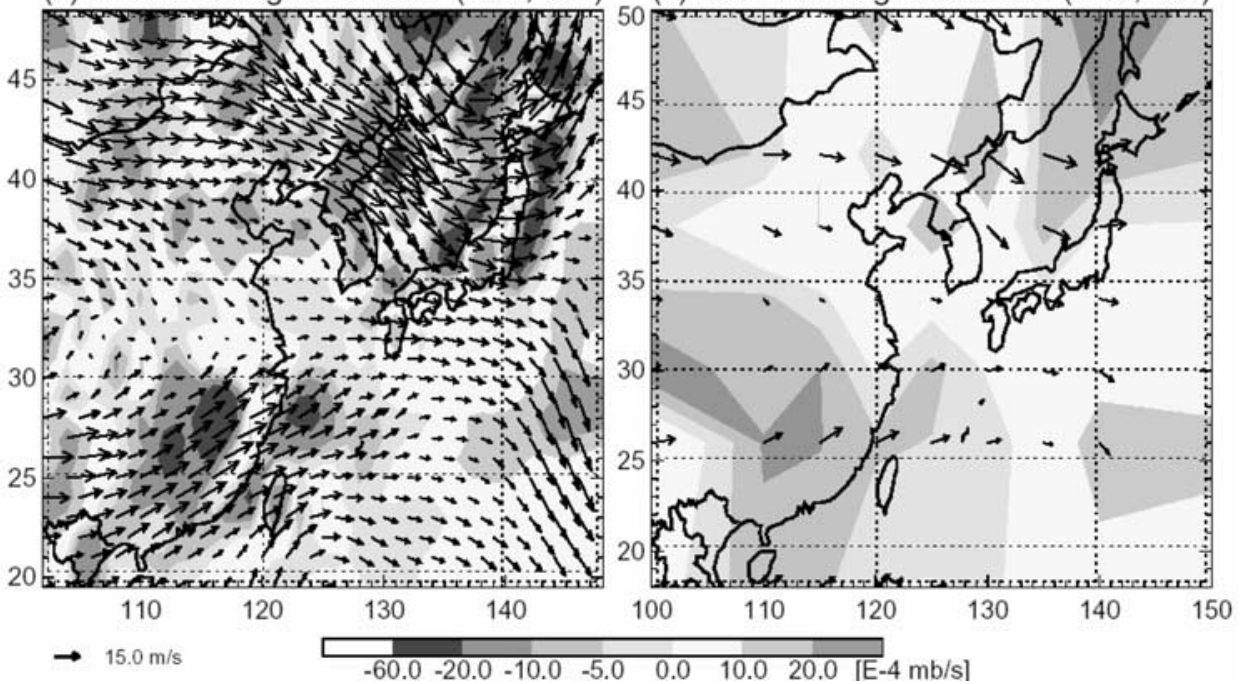

Figure 14. (a) $\mathrm{CO}$ observations (colored line) along the flight track of $\mathrm{P}-3 \mathrm{~B}$ flight 16 and wind vectors at $2 \mathrm{~km}$ (black arrows) on 23 March 2001. Direction changes of this flight are marked by A/B/C. (b) Vertical velocity $\omega$ (color coding; unit: $\mathrm{mb} / \mathrm{s}$ ) for 23 March 2001, calculated using the high-resolution model. (c) Vertical velocity $\omega$ and wind vectors at $2 \mathrm{~km}$ (black arrows) for 23 March 2001, calculated by the coarse-resolution model. See color version of this figure at back of this issue.

tion could be reduced if we were to assume that emissions assumed for China should be increased, consistent with conclusions reached earlier on the basis of an inversion study by Palmer et al. [2003] based on the GEOS-CHEM global model with $2^{\circ} \times 2.5^{\circ}$ resolution.

[42] The P-3B flight on 23 March 2001 (flight number P16) sampled air both to the north and south of Japan. The flight originated and terminated in Yokota (near Tokyo). Observations along the flight track are summarized in Figure 14a. Concentrations of CO measured in the boundary layer to the south are systematically higher than those to the north $(350 \mathrm{ppb}$ as compared to $200 \mathrm{ppb}$ ). The high-resolution model captures reasonably well the north to south gradient of concentrations observed in the boundary layer, though it tends to underestimate concentrations to the south by about
$50 \mathrm{ppb}$ (Figure 15a). The tagged tracer simulation indicates that $\mathrm{CO}$ from central and south China (south of $32^{\circ} \mathrm{N}$ and east of $110^{\circ} \mathrm{E}$ ) is largely responsible for the high concentrations of $\mathrm{CO}$ observed in the boundary layer to the south (Figure 15b, part A). The surface wind pattern (not shown) indicates a strong marine influence to the south of China with a general onshore flow from the northeast along the coast. This onshore flow pattern tends to inhibit direct advection of emissions from the Chinese mainland to southern regions of Japan. Winds at $2 \mathrm{~km}$ indicate a cyclonic flow pattern to the north of Japan with an anticyclonic flow dominating to the south over the East China Sea (Figure 14a). The anticyclone is associated with upward motion to the west (i.e., west of $130^{\circ} \mathrm{E}$ ) with downward motion to the east as indicated in Figure 14b. As a consequence, $\mathrm{CO}$ emitted from central and south 
(a) TRACEP P3B-16 observed and modeled CO

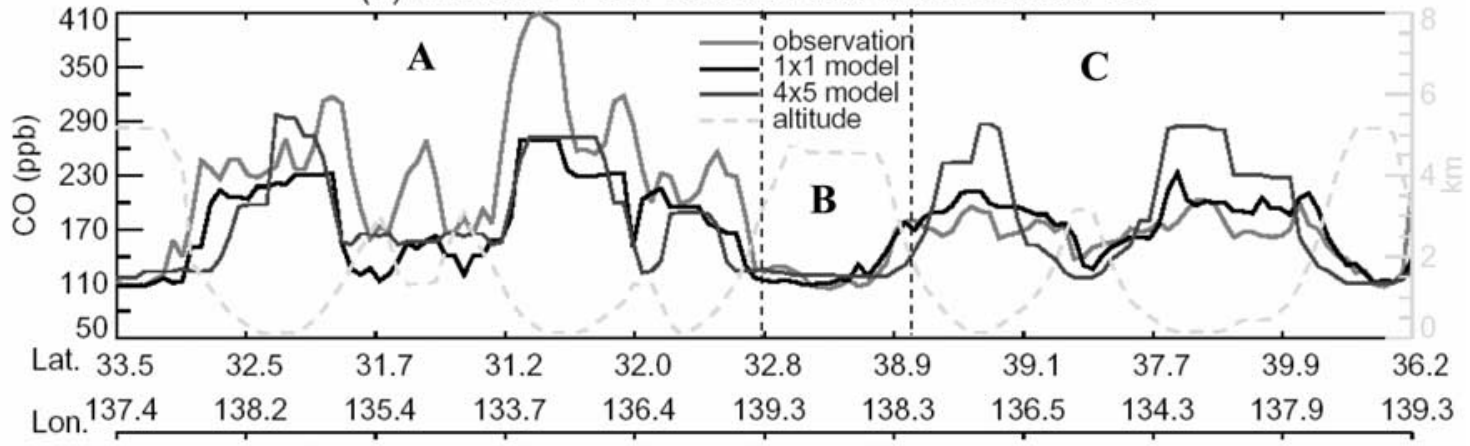

(b) Contributions from tagged tracers

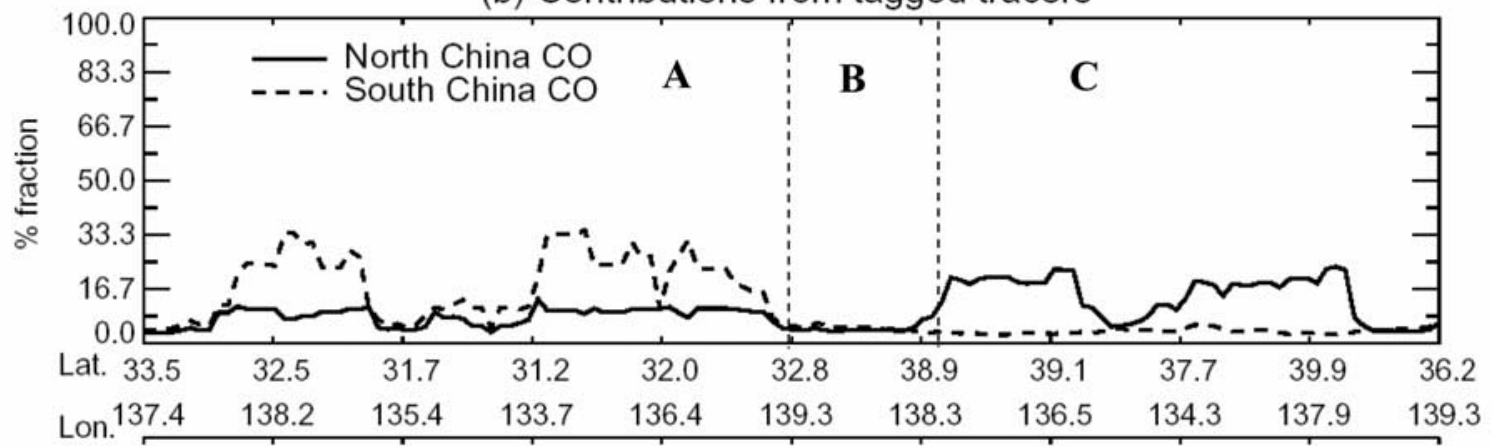

Figure 15. (a) Comparison of $\mathrm{CO}$ observations made by $\mathrm{P}-3 \mathrm{~B}$ flight 16 (red line) with model results obtained from the high-resolution model (black line) and with model results from the coarse-resolution model (blue line) along flight track of P3B flight 16 on 23 March 2001. Flight altitude is shown by the dashed green line. The $x$ axis is time but labeled in latitude and longitude along the flight track. Direction changes are indicated by $\mathrm{A} / \mathrm{B} / \mathrm{C}$ corresponding to Figure $14 \mathrm{a}$. (b) Simulated percentage contributions from emissions in north China (north of $32^{\circ} \mathrm{N}$ and east of $110^{\circ} \mathrm{E}$ ) (solid black line) and south China (south of $32^{\circ} \mathrm{N}$ and east of $110^{\circ} \mathrm{E}$ ) (dashed black line) along the flight track. See color version of this figure at back of this issue.

China (to the west of the anticyclone) is first uplifted and then transported to the northeast, subsiding eventually to the south of Japan (on the eastern edge of the anticyclone). Conversely, the cyclone in the north is associated with subsidence to the west and upwelling to the east. As a consequence, $\mathrm{CO}$ emitted from northern China (west of the cyclone) is confined mainly to the boundary layer and is transported by the cyclonic flow at the surface primarily to the northeast and eventually to the east. This combination of circumstances accounts for the predominant importance of emissions from south China in accounting for the observations of $\mathrm{CO}$ in the boundary layer south of $33^{\circ} \mathrm{N}$ and for the significance of emissions from North China in the context of the observations from the region north of $37^{\circ} \mathrm{N}$ as indicated in Figure $15 \mathrm{~b}$. The model tends to underestimate concentrations of $\mathrm{CO}$ in the south although agreement between model and observations for the north is excellent (Figure 15a). The overall agreement between model and observation would be improved if emissions from the south were increased.

[43] The coarse-resolution model tends to overestimate $\mathrm{CO}$ concentrations in the north and fails notably to account for the north-south gradient observed in the boundary layer (Figure 15a). The difference between the low- and highresolution models may be attributed to the inability of the low-resolution model to resolve the boundary separating the regions of cyclonic and anticyclonic flow (Figure 14c).

\section{Concluding Remarks}

[44] The nested grid methodology developed here allows us to treat the chemistry of a particular region with relatively high spatial resolution while at the same time preserving the ability of the model to simulate the interaction of this region with the larger global environment. The global model is run as usual over the whole globe, including the nested domain. Results from the coarse global model simulation are used to drive the fine-resolution model through boundary conditions defined by the low-resolution model, but not vice versa (oneway nesting). The spatial resolution adopted here for the higher-resolution window, $1^{\circ} \times 1^{\circ}$, appears to provide a better account of the meteorological features primarily responsible for the spatial redistribution of chemical species over east Asia during early spring, the period selected for the present investigation than does the global model at $4^{\circ} \times 5^{\circ}$ resolution.

[45] Results for CO from three models were compared: the nested grid model $\left(1^{\circ} \times 1^{\circ}\right.$ resolution $)$, the coarse global model $\left(4^{\circ} \times 5^{\circ}\right)$, and the intermediate global model $\left(2^{\circ} \times 2.5^{\circ}\right)$. Mixing ratios of $\mathrm{CO}$ predicted by the coarse 
global model are significantly higher than those for the high-resolution nested model at lower altitudes. Results from the intermediate global model are intermediate between the coarse global model and the nested grid model, closer to the latter. Differences between results obtained with the high- and low-resolution models mainly reflect the significance of localized regions of intense upward advection responsible for removal of chemicals from the near surface environment. The mixing ratio of pollutants (CO in this study) usually decreases rapidly with altitude. The flux of $\mathrm{CO}$ associated with upward advective motion is thus significantly greater than the flux associated with downward motion. Under circumstances for which there is a significant variation in vertical velocities (defined at a resolution of $1^{\circ} \times 1^{\circ}$ ) over a grid element of the lowresolution model, vertical advective transport of $\mathrm{CO}$ computed on the scale of the $4^{\circ} \times 5^{\circ}$ model using velocities averaged over the grid can differ therefore from the average of fluxes computed using the higher-resolution model. The failure of the low-resolution model to account for subgrid vertical motions can be resolved through a carefully designed and broadly tested eddy diffusion treatment. This would not eliminate, however, the need for the higher spatial resolution in the parent data that appears to be required to capture the variability of vertical motions. The diffusion coefficients for the low-resolution model have to be calculated from the archived vertical velocities represented in the high-resolution simulation.

[46] Other factors, such as boundary layer turbulent and correlations between emissions and boundary layer venting, are found to play but a minor role in accounting for the differences between model solutions. Budget analysis of $\mathrm{CO}$ suggests that upward transfer to higher altitudes through large-scale advection provides the major sink for $\mathrm{CO}$ below $4 \mathrm{~km}$. Despite the polluted nature of the Asia/China study region, horizontal advection contributes a net source of $\mathrm{CO}$ to the entire window domain. $\mathrm{CO}$ is imported mainly through the north boundary, reflecting long range transport of $\mathrm{CO}$ from Europe to Asia. Imported $\mathrm{CO}$ amounts to more than $30 \%$ of internally emitted $\mathrm{CO}$ for window regions north of $30^{\circ} \mathrm{N}$ and about $20 \%$ of internal $\mathrm{CO}$ over polluted regions in south and east China. Time-varying boundary conditions are essential if the model is to simulate the nontrivial impact of outside emissions on the study region.

[47] The nested-grid model is shown to provide good agreement with $\mathrm{CO}$ measurements made during the TRACE-P campaign in spring 2001, with a typical correlation of greater than 0.7. It fares better than the low-resolution model in capturing the variability of concentrations implied by the observations, notably in simulating frontal lifting process and differences across the boundary separating regions of cyclonic and anticyclonic flow. Chemicals emitted over Asia (CO in this study) are transferred eastward through a two step process. First they are lifted through bulk vertical motions of the atmosphere from the near surface region to higher altitudes. Subsequently they are captured by the westerlies that dominate the meteorological regime in the middle troposphere. Lifting ahead of southeastward moving cold fronts is responsible for an important pathway transporting $\mathrm{CO}$ emitted from southern China (south of $32^{\circ} \mathrm{N}$ and east of $\left.110^{\circ} \mathrm{E}\right)$ to the free troposphere. $\mathrm{CO}$ emitted from northern China (north of $32^{\circ} \mathrm{N}$ and east of $110^{\circ} \mathrm{E}$ ) is confined mainly to the boundary layer due to the large-scale subsidence associated with the semipermanent Siberia High to the northwest and is occasionally transported to the east by eastward moving, transient, middle latitude cyclones. Upwelling associated with these cyclones provides an important pathway to the free troposphere of emissions originated in northern China.

[48] Acknowledgments. This research was funded in part by a grant from the V. Kann Rasmussen Foundation as part of the China Project of the Harvard University Center for the Environment and in part by the National Science Foundation, grant ATM-0236501. Development of the GEOSCHEM model was funded by the NASA Atmospheric Chemistry Modeling and Analysis Program (ACMAP). We thank Hongyu Liu, Jennifer Logan, and Brian Farrell for helpful discussions and the referees, including Mark Lawrence, for valuable suggestions that contributed to important improvements in the final presentation of the paper.

\section{References}

Alapaty, K., R. Mathur, and T. Odman (1998), Intercomparison of spatial interpolation schemes for use in nested grid models, Mon. Weather Rev, 126, 243-249.

Allen, D. J., R. B. Rood, A. M. Thompson, and R. D. Hudson (1996), Three dimensional radon 222 calculations using assimilated meteorological data and a convective mixing algorithm, J. Geophys. Res., 101, 6871-6881.

Allen, D., K. Pickering, and G. Stenchikov (2000), A three-dimensional total odd nitrogen (NOy) simulation during SONEX using a stretchedgrid chemical transport model, J. Geophys. Res., 105(D3), 3851-3876.

Bey, I., D. J. Jacob, R. M. Yantosca, J. A. Logan, B. Field, A. M. Fiore, Q. Li, H. Liu, L. J. Mickley, and M. Schultz (2001a), Global modeling of tropospheric chemistry with assimilated meteorology: Model description and evaluation, J. Geophys. Res., 106, 23,073-23,096.

Bey, I., D. J. Jacob, J. A. Logan, and R. M. Yantosca (2001b), Asian chemical outflow to the Pacific: Origins, pathways and budgets, J. Geophys. Res., 106, 23,097.

Duncan, B. N., R. V. Martin, A. C. Staudt, R. Yevich, and J. A. Logan (2003), Interannual and seasonal variability of biomass burning emissions constrained by satellite observations, J. Geophys. Res., 108(D2), 4100, doi:10.1029/2002JD002378.

Fiore, A., D. J. Jacob, I. Bey, R. M. Yantosca, B. D. Field, A. C. Fusco, and J. G. Wilkinson (2002), Background ozone over the United States in summer: Origin, trend, and contribution to pollution episodes, J. Geophys. Res., 107(D15), 4275, doi:10.1029/2001JD000982.

Fiore, A., D. J. Jacob, H. Liu, R. M. Yantosca, T. D. Fairlie, and Q. Li (2003), Variability in surface ozone background over the United States: Implications for air quality policy, J. Geophys. Res., 108(D24), 4787, doi:10.1029/2003JD003855

Fuelberg, H. E., C. M. Kiley, J. R. Hannan, D. J. Westberg, M. A. Avery, and R. E. Newell (2003), Meteorological conditions and transport pathways during the Transport and Chemical Evolution over the Pacific (TRACE-P) experiment, J. Geophys. Res., 108(D20), 8782, doi:10.1029/2002JD003092.

Heald, C. L., D. J. Jacob, P. I. Palmer, M. J. Evans, G. W. Sachse, H. B. Singh, and D. R. Blake (2003), Biomass burning emission inventory with daily resolution: Application to aircraft observations of Asian outflow, J. Geophys. Res., 108(D21), 8811, doi:10.1029/2002JD003082.

Holton, J. R. (1992), An Introduction to Dynamic Meteorology, 3rd ed., Academic, San Diego, Calif.

Jacob, D. J., J. H. Crawford, M. M. Kleb, V. S. Connors, R. J. Bendura, J. L. Raper, G. W. Sachse, J. C. Gille, L. Emmons, and C. L. Heald (2003), Transport and Chemical Evolution over the Pacific (TRACE-P) aircraft mission: Design, execution, and first results, J. Geophys. Res., 108(D20), 9000, doi:10.1029/2002JD003276.

Jakobs, H. J., H. Feldmann, H. Hass, and M. Memmesheimer (1995), The use of nested models for air pollution studies: An application of the EURAD model to a SANA episode, J. Appl. Meteorol., 34, 1301-1319.

Jöckel, P., R. von Kuhlmann, M. G. Lawrence, S. Steil, C. A. M. Brenninkmeijier, P. J. Crutzen, P. J. Rasch, and B. Eaton (2001), On a fundamental problem in implementing flux-form advection schemes for tracer transport in 3-dimensional general circulation and chemistry transport models, Q. J. R. Meteorol. Soc., 127, 1035-1052.

Kiley, C. M., et al. (2003), An intercomparison and evaluation of aircraftderived and simulated $\mathrm{CO}$ from seven chemical transport models during the TRACE-P experiment, J. Geophys. Res., 108(D21), 8819, doi:10.1029/2002JD003089.

Kim, J., and S. Y. Cho (1999), Application of the nested grid STEM to an early summer acid rain in South Korea, Atmos. Environ., 33, 3167-3181. 
Lam, K. S., T. J. Wang, L. Y. Chan, T. Wang, and J. Harris (2001), Flow patterns influencing the seasonal behavior of surface ozone and carbon monoxide at a coastal site near Hong Kong, Atmos. Environ., 35, 3121 3135 .

Langmann, B., S. E. Bauer, and I. Bey (2003), The influence of the global photochemical composition of the troposphere on European summer smog, Part I: Application of a global to mesoscale model chain, J. Geophys. Res., 108(D4), 4146, doi:10.1029/2002JD002072.

Lau, K. M., and M. T. Li (1984), The monsoon of east Asia and its global associations, Bull. Am. Meteorol. Soc., 65(2), 114-125.

Lawrence, M. G., et al. (2003), Global chemical weather forecasts for field campaign planning: Predictions and observations of large-scale features during MINOS, CONTRACE, and INDOEX, Atmos. Chem. Phys., 3 , 267-289.

Li, Q. B., et al. (2001), A tropospheric ozone maximum over the Middle East, Geophys. Res. Lett., 28, 3235-3238.

Lin, S.-J., and R. B. Rood (1996), Multidimensional flux form semiLagrangian transport schemes, Mon. Weather Rev., 124, 2046-2070.

Liu, H., W. L. Chang, S. J. Oltmans, L. Y. Chan, and J. M. Harris (1999), On springtime high ozone events in the lower troposphere from southeast Asian biomass burning, Atmos. Environ., 33, 2403-2410.

Liu, H., D. J. Jacob, L. Y. Chan, S. J. Oltmans, I. Bey, R. M. Yantosca, J. M. Harris, B. N. Duncan, and R. V. Martin (2002), Sources of tropospheric ozone along the Asian Pacific Rim: An analysis of ozonesonde observations, J. Geophys. Res., 107(D21), 4573, doi:10.1029/2001JD002005.

Liu, H., D. J. Jacob, I. Bey, R. M. Yantosca, B. N. Duncan, and G. W. Sachse (2003), Transport pathways for Asian pollution outflow over the Pacific: Interannual and seasonal variations, J. Geophys. Res., 108(D20), 8786, doi:10.1029/2002JD003102.
Palmer, P. I., D. J. Jacob, D. B. A. Jones, C. L. Heald, R. M. Yantosca, J. A. Logan, G. W. Sachse, and D. G. Streets (2003), Inverting for emissions of carbon monoxide from Asia using aircraft observations over the western Pacific, J. Geophys. Res., 108(D21), 8828, doi:10.1029/2003JD003397.

Pleim, J. E., J. S. Chang, and K. Zhang (1991), A nested grid mesoscale atmospheric chemistry model, J. Geophys. Res., 96(D2), 30653084.

Schubert, S. D., R. B. Rood, and J. Pfaendtner (1993), An assimilated data set for earth science applications, Bull. Am. Meteorol. Soc., 74, $2331-$ 2342.

Seinfeld, J. H., and S. N. Pandis (1998), Atmospheric Chemistry and Physics: From Air Pollution to Climate Change, John Wiley, Hoboken, N. J. Streets, D. G., et al. (2003), An inventory of gaseous and primary aerosol emissions in Asia in the year 2000, J. Geophys. Res., 108(D21), 8809, doi:10.1029/2002JD003093.

Yevich, R., and J. A. Logan (2003), An assessment of biofuel use and burning of agricultural waste in the developing world, Global Biogeochem. Cycles, 17(4), 1095, doi:10.1029/2002GB001952.

Zhang, Y., K. R. Sperber, and J. S. Boyle (1997), Climatology and interannual variation of the east Asian winter monsoon: Results from the 1979-95 NCEP/NCAR reanalysis, Mon. Weather Rev., 125, $2605-2619$.

D. J. Jacob, M. B. McElroy, Y. X. Wang, and R. M. Yantosca, Department of Earth and Planetary Science and Division of Engineering and Applied Sciences, Harvard University, 29 Oxford Street, Cambridge, MA 02138, USA. (wang3@fas.harvard.edu) 
a) Terrain Elevations $(1 \times 1)$

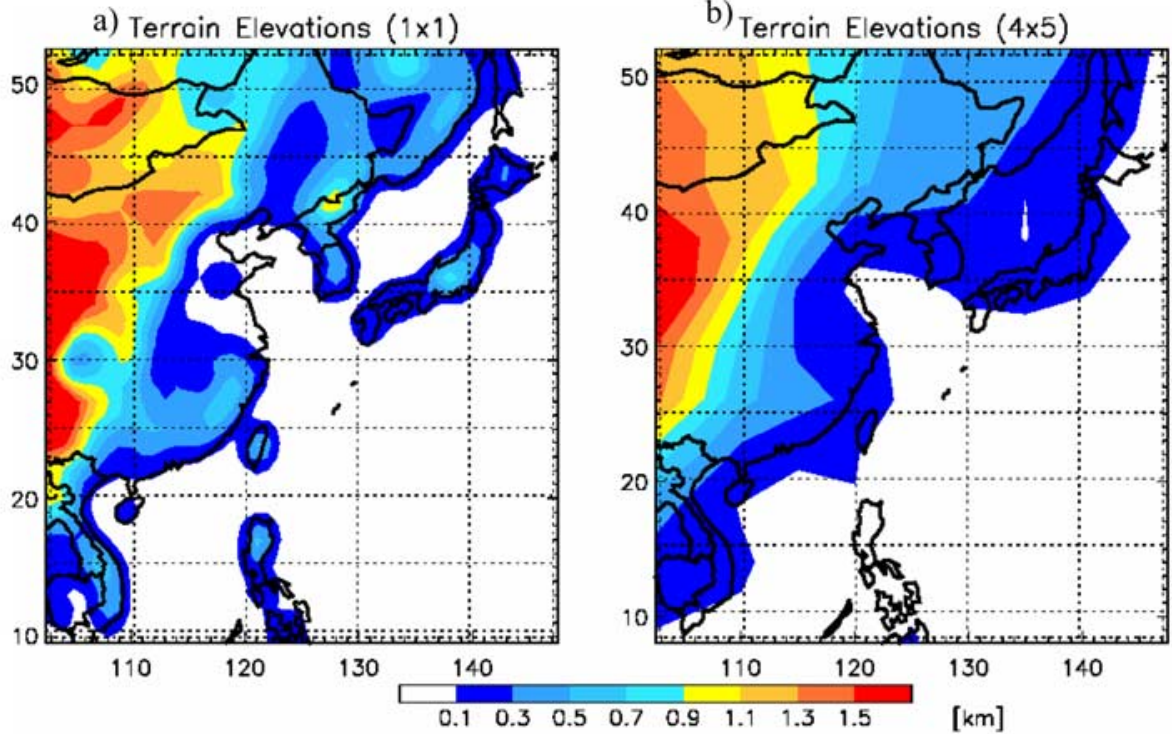

c) Terrain elevations at high resolution

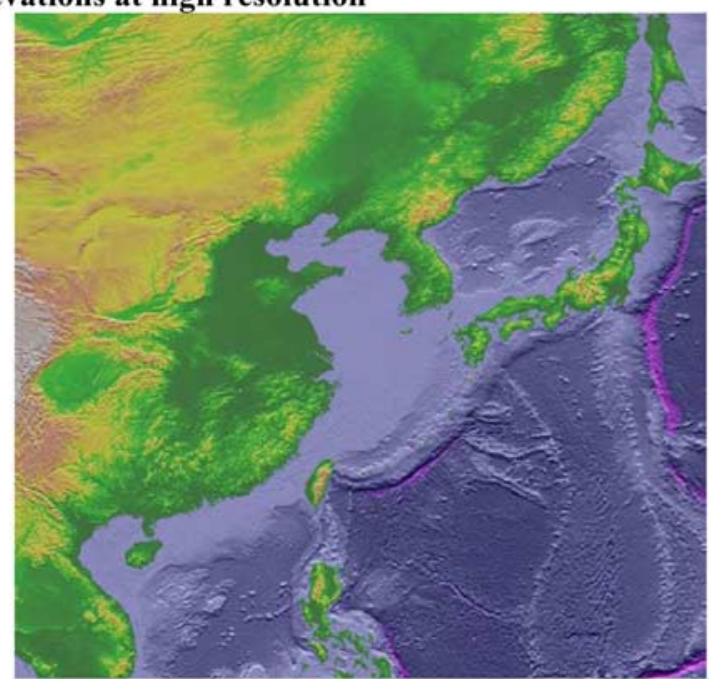

Figure 2. GEOS terrain elevations for the window region at (a) $1^{\circ} \times 1^{\circ}$ and (b) $4^{\circ} \times 5^{\circ}$ resolution. (c) High-resolution (3 arc-minute grid) topography image from NOAA National Data Centers is shown for comparison (ftp://ftp.ngdc.noaa.gov/GLOBE_DEM/pictures/GLOBALeb3colshade.jpg). 
a) $\mathrm{CO}$ emissions for Mar 2001 (1x1)

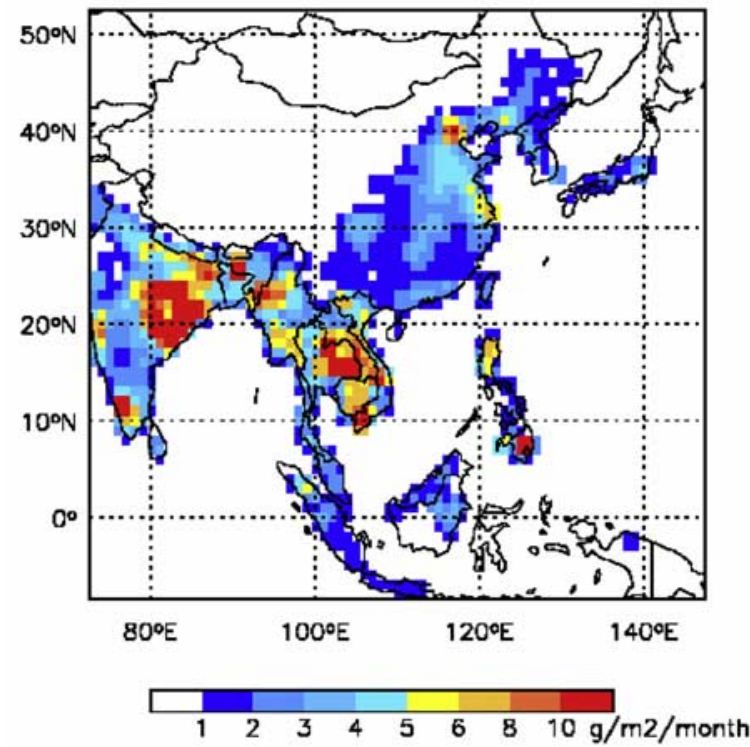

b) North and NE. China (4x5)

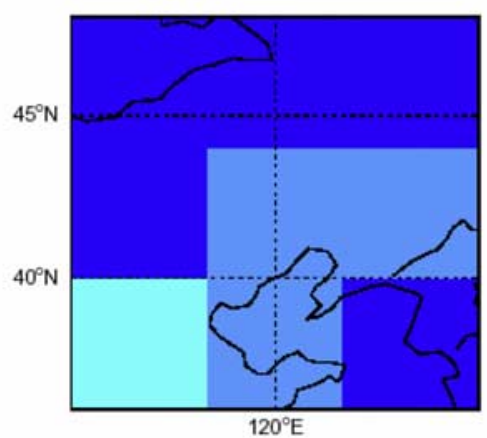

$120^{\circ} \mathrm{E}$

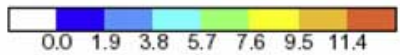

North and NE. China $(1 \times 1)$

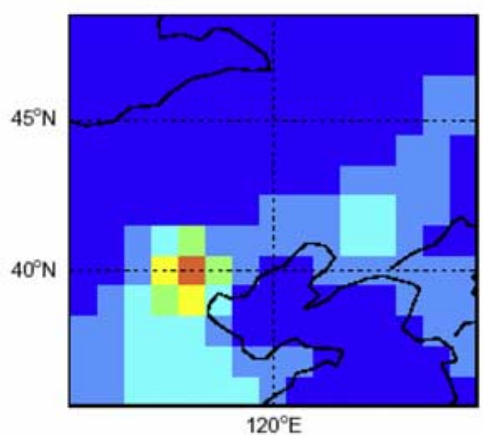

c) Pearl River Delta $(4 \times 5)$

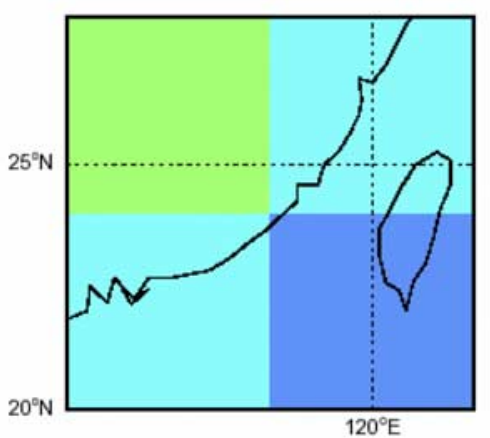

g/m2/month

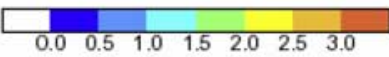

Pearl River Delta (1x1)

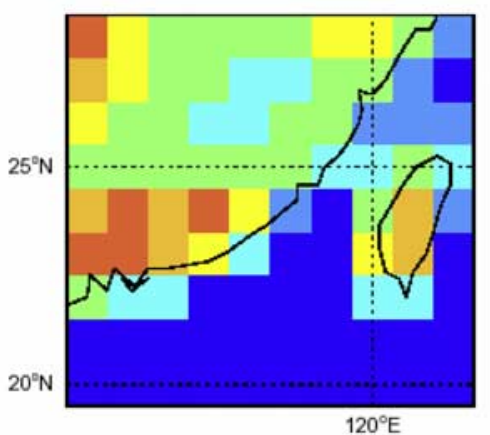

d) Sichuan Basin $(4 \times 5)$

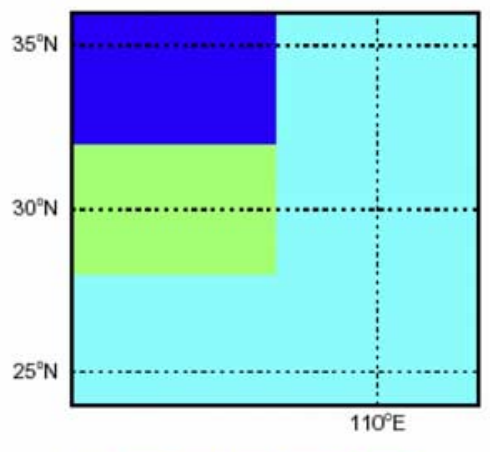

g/m2/mont

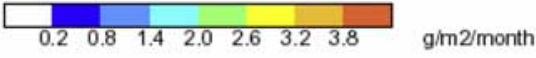

Sichuan Basin (1x1)

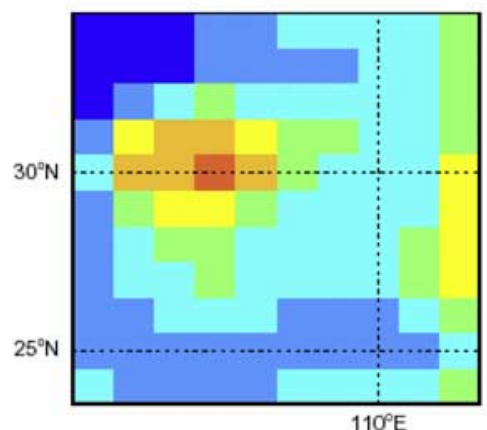

Figure 3. (a) Total $\mathrm{CO}$ emissions for the window region, represented by the $1^{\circ} \times 1^{\circ}$ nested model. Comparison of composite $\mathrm{CO}$ emissions at $1^{\circ} \times 1^{\circ}$ and $4^{\circ} \times 5^{\circ}$ resolution for several selected grids in (b) north and northeastern China, (c) Pearl River Delta, and (d) Sichuan Basin. Units are $\mathrm{g} / \mathrm{m}^{2} / \mathrm{month}$. Note that the color scale is different in each panel. 


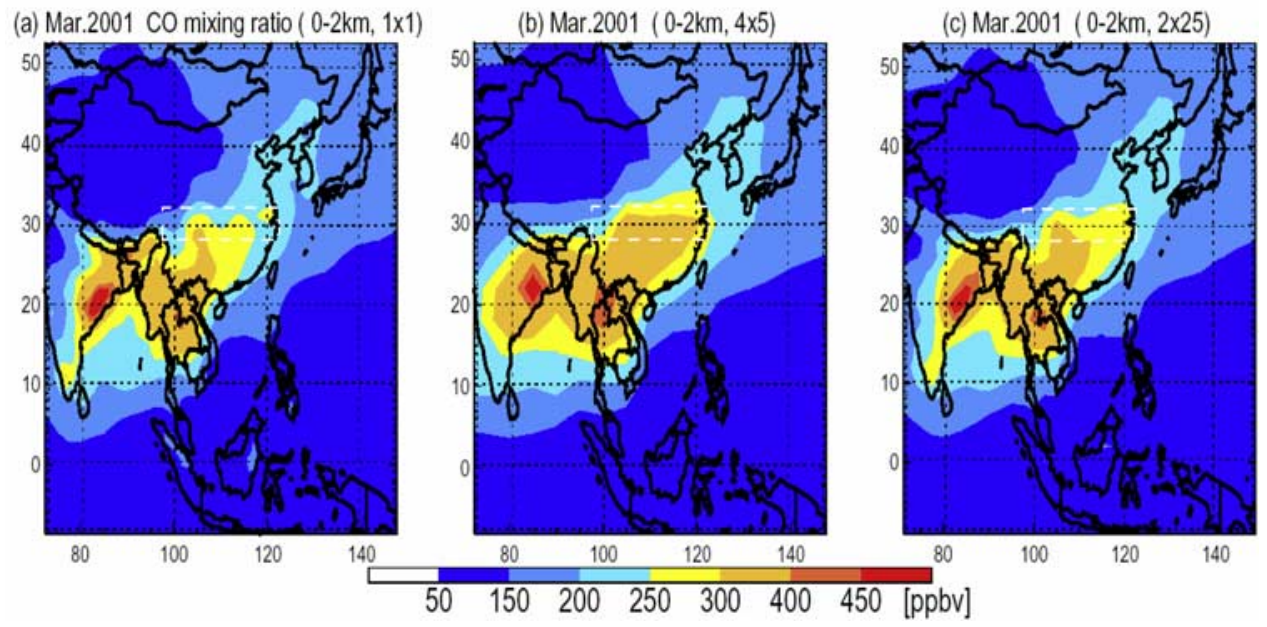

Figure 4. Comparisons of $\mathrm{CO}$ mixing ratios averaged between 0 and $2 \mathrm{~km}$ for March 2001, simulated by (a) the fine-resolution $\left(1^{\circ} \times 1^{\circ}\right)$ nested model, (b) the coarse-resolution $\left(4^{\circ} \times 5^{\circ}\right)$ global model, and (c) the intermediate-resolution $\left(2^{\circ} \times 2.5^{\circ}\right)$ global model. The central China region is defined by the dashed white rectangle in each panel. 
(a) Mar1-31 Omega at 4km Central China
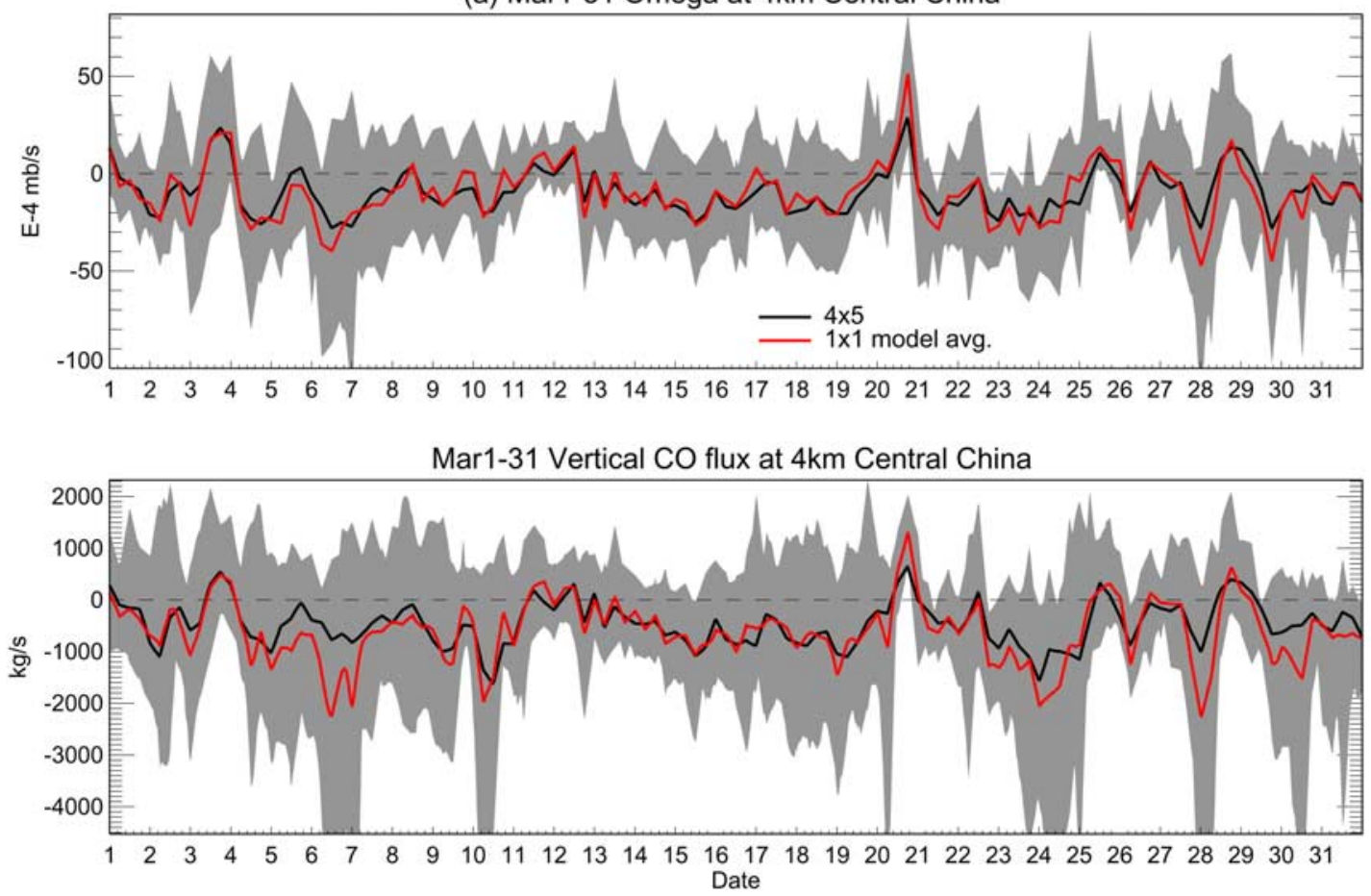

(b) Mar1-31 Omega at 4km YRD
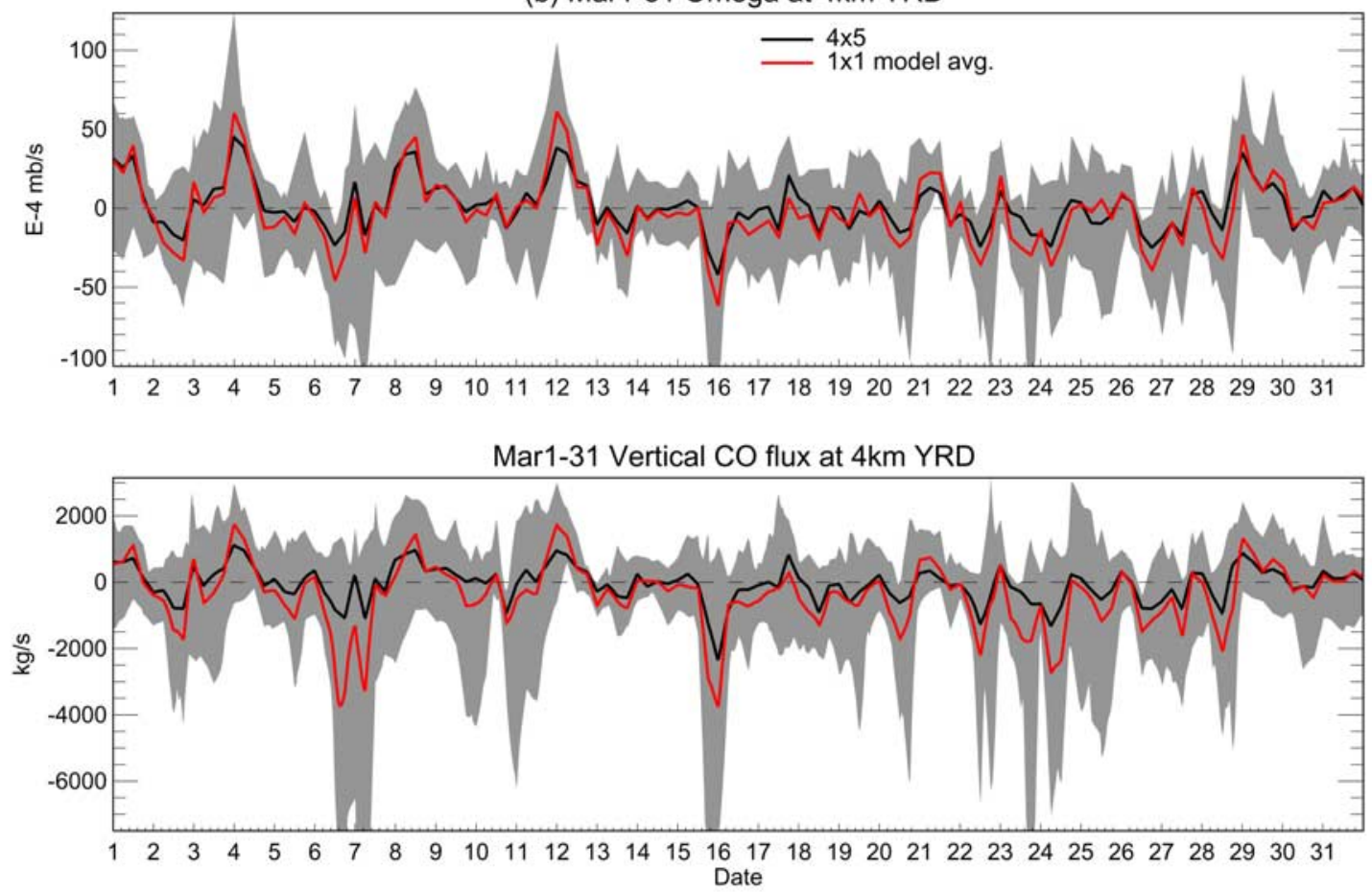

Figure 6 
Figure 6. (a) Time series of vertical velocity $\omega$ (upper), and vertical CO fluxes (lower) at $4 \mathrm{~km}$ for one $4^{\circ} \times 5^{\circ}$ grid element centered at $\left(30^{\circ} \mathrm{N}, 110^{\circ} \mathrm{E}\right)$ in the central China region. The thick black line depicts results from the coarseresolution global model. Values obtained by averaging results from the fine-resolution nested model are indicated by the red line. The gray shaded area indicates the range of results from the high-resolution model prior to spatial averaging. (b) The same as Figure $6 \mathrm{a}$, but for a $4^{\circ} \times 5^{\circ}$ grid element centered at $\left(30^{\circ} \mathrm{N}, 120^{\circ} \mathrm{E}\right)$ in Yangtze River Delta (YRD) region. 
a) Mor 7 Vertical CO flux $(2 \mathrm{~km}, 1 \times 1)$

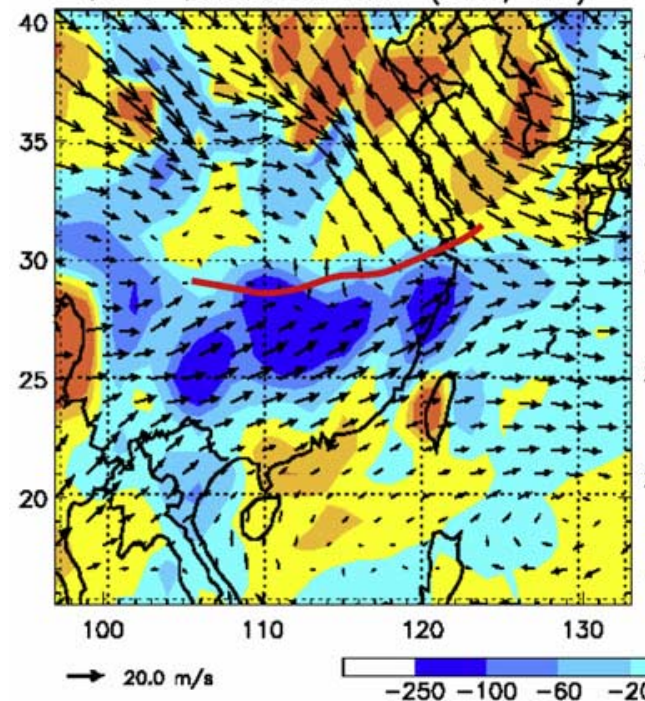

b) $\mathrm{CO}$ flux and wind $(2 \mathrm{~km}, 4 \times 5)$

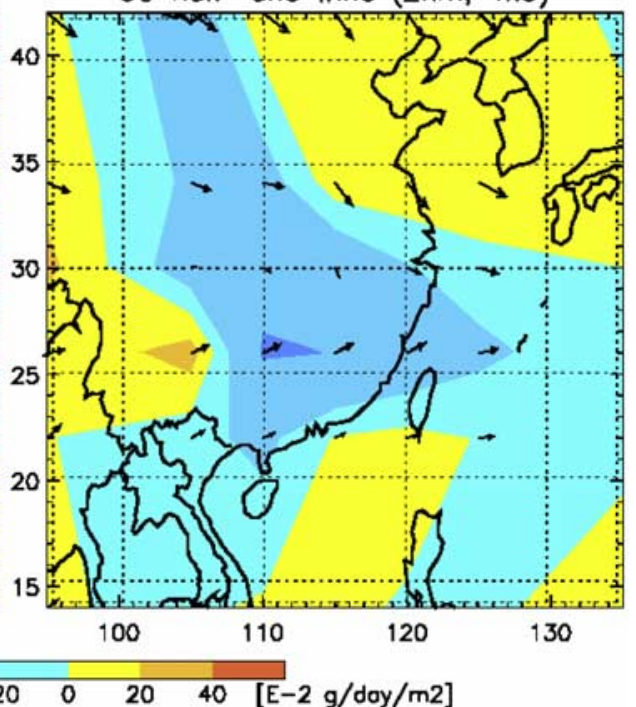

Figure 7. Wind vectors (black arrows) and vertical CO fluxes (color coding; unit: $\mathrm{gCO} / \mathrm{day} / \mathrm{m}^{2}$ ) at $2 \mathrm{~km}$ over the central China region for 7 March 2001, as calculated by (a) the high-resolution model and (b) the coarse-resolution model. Negative flux refers to upward motion and positive flux refers to downward motion. The thick red line in Figure 7a indicates the approximate location of a cold front at $2 \mathrm{~km}$.

(a) $0-2 \mathrm{~km}$

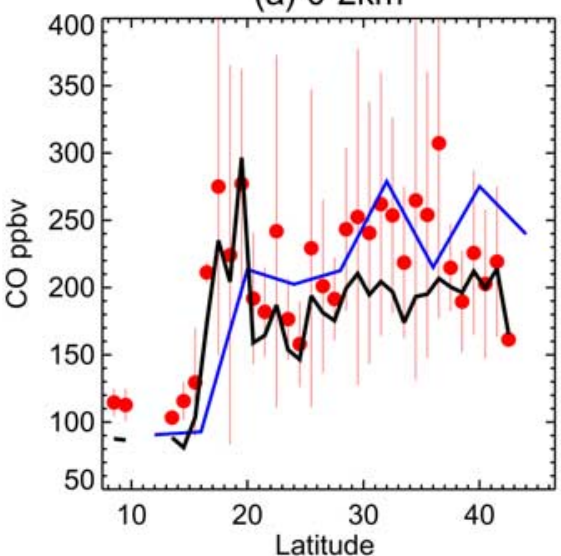

(b) $2-4 \mathrm{~km}$

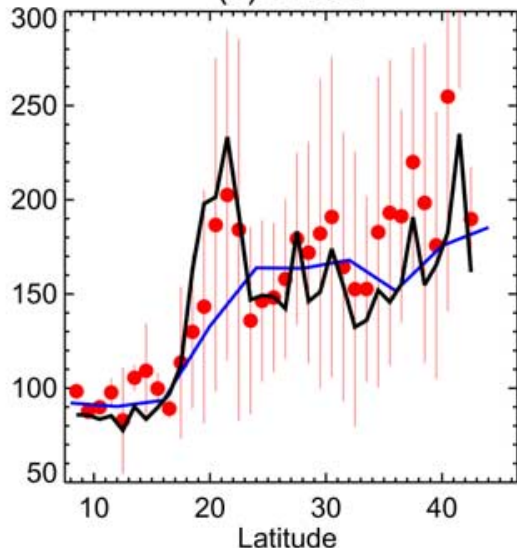

(c) $>4 \mathrm{~km}$

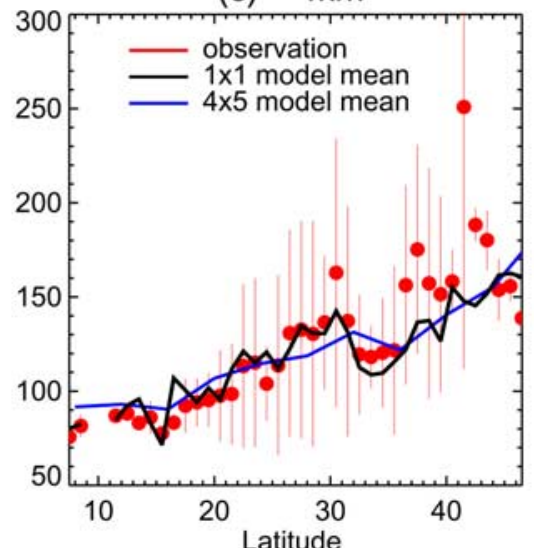

Figure 10. Latitudinal distribution of measured and modeled CO during TRACE-P. Data are shown for three altitude ranges of (a) $0-2 \mathrm{~km}$, (b) $2-4 \mathrm{~km}$, and (c) $>4 \mathrm{~km}$. For each altitudinal range, observations are averaged over $1^{\circ}$ latitudinal bins. Red dots denote the mean observed values and red vertical bars denote 1- $\sigma$ values about the mean. The mean values of the high-resolution $\left(1^{\circ} \times 1^{\circ}\right)$ model results are shown by the black line. Those of the coarse-resolution $\left(4^{\circ} \times 5^{\circ}\right)$ model results are shown in blue. 
a) DC8 Flight $\$ 7$ co obs. and surface winds

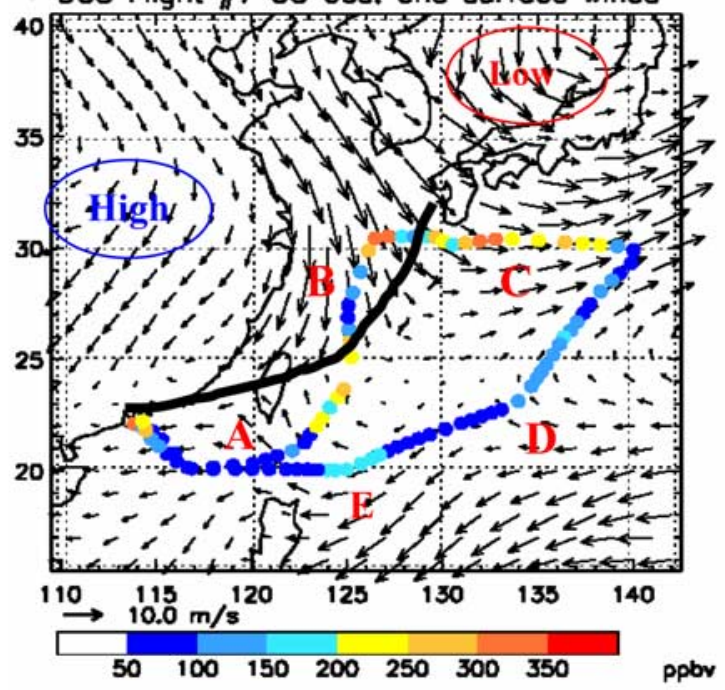

(b) TRACEP DC8-7 and 1x1 Model

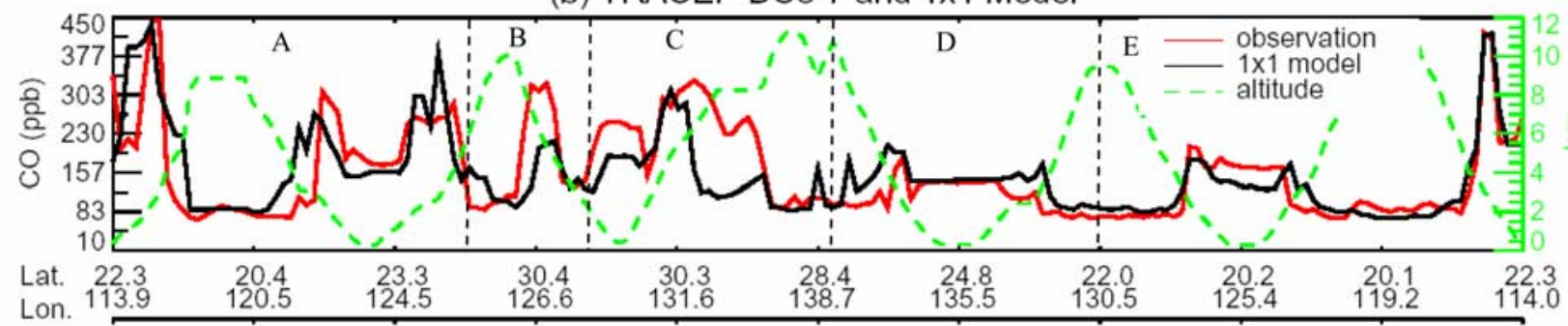

(c) TRACEP DC8-7 and $4 \times 5$ Model

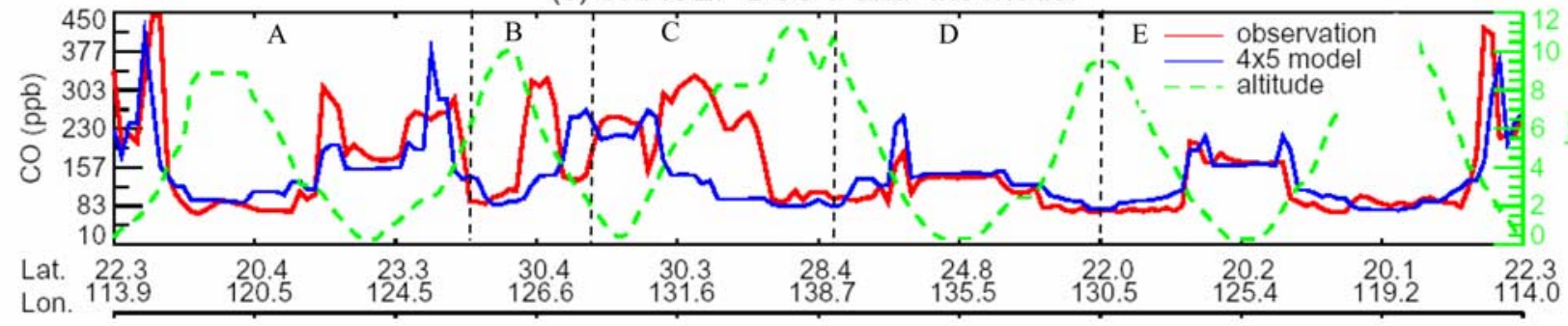

(d) Contributions from tagged tracers

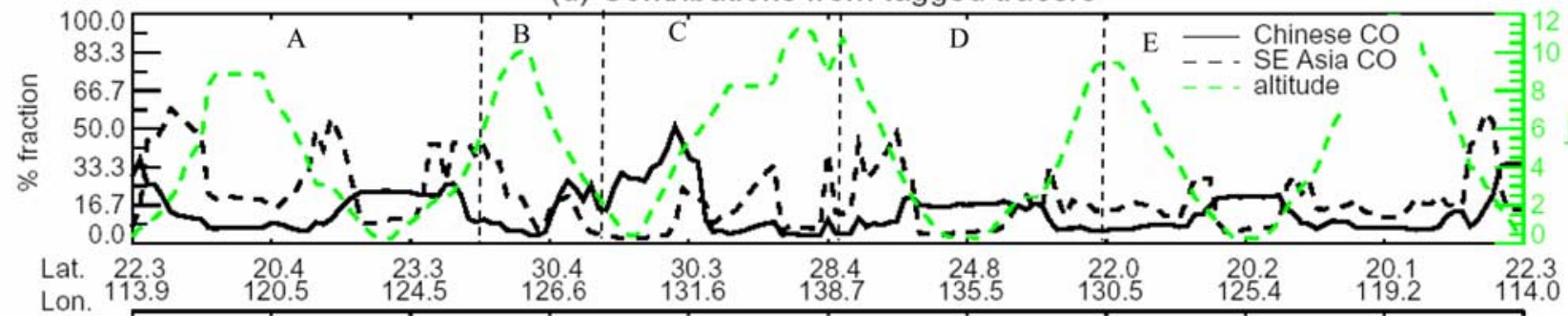

Figure 13. (a) Flight track (colored line) of DC-8 flight 7 during TRACE-P and surface wind vectors on 7 March 2001. The colors indicate CO mixing ratios observed along the flight track. Direction changes of this flight are marked by $\mathrm{A} / \mathrm{B} / \mathrm{C} / \mathrm{D} / \mathrm{E}$. The thick black line shows the approximate location of a surface cold front. (b) $\mathrm{CO}$ observations made by DC-8 flight 7 (red line) and CO concentrations simulated by the high-resolution model (black line) along flight track on 7 March 2001. Flight altitude is shown by the dashed green line. The $x$ axis is time but labeled in latitude and longitude along the flight track. Flight direction changes are indicated by $\mathrm{A} / \mathrm{B} / \mathrm{C} / \mathrm{D} / \mathrm{E}$ corresponding to Figure 13a. (c) The same as Figure 13b, but for $\mathrm{CO}$ simulated by the coarse-resolution model (blue line). (d) Simulated percentage contributions from Chinese CO sources (solid black line) and southeast Asian CO sources (dashed black line) along the flight track. 


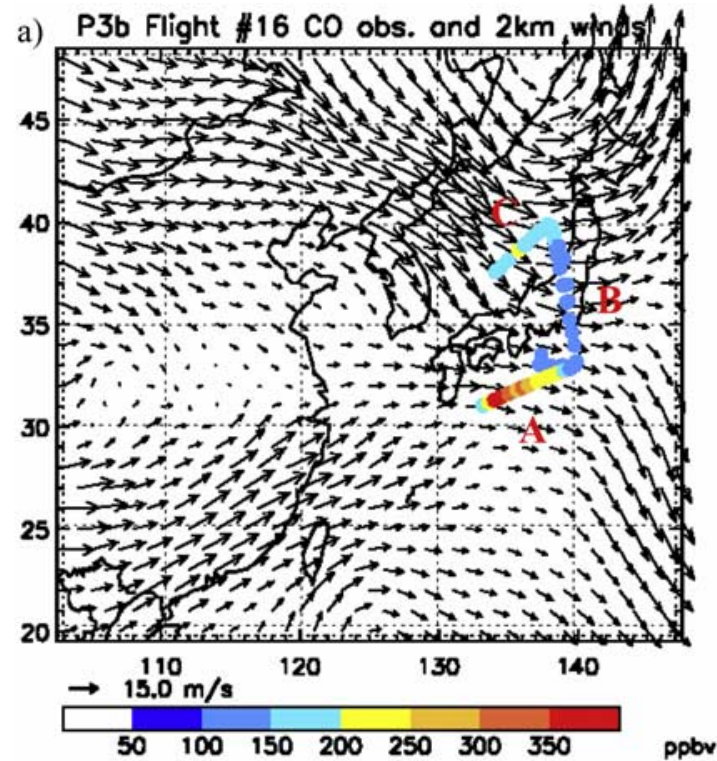

(b) Mar 23 Omega and wind (2km, 1x1)

(c) Mar 23 Omega and wind $(2 \mathrm{~km}, 4 \times 5)$
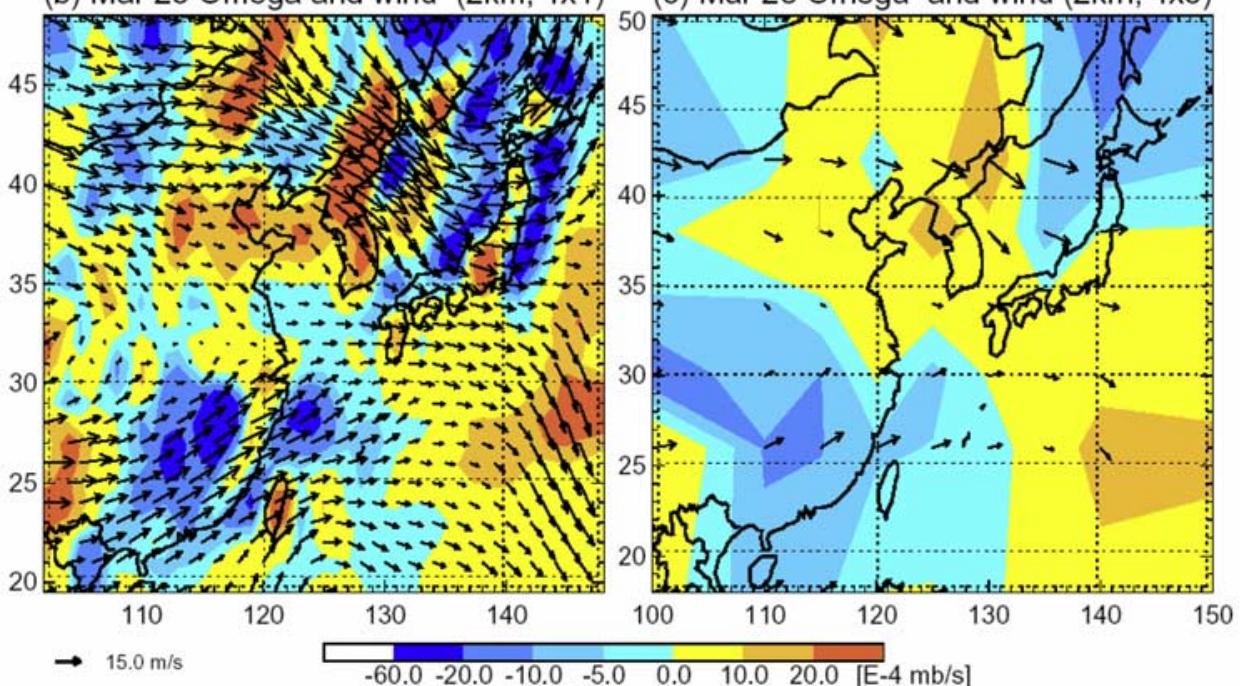

$\left.\begin{array}{lll}0.0 & 10.0 & 20.0\end{array}\right]$ E 4 mb/s]

Figure 14. (a) $\mathrm{CO}$ observations (colored line) along the flight track of $\mathrm{P}-3 \mathrm{~B}$ flight 16 and wind vectors at $2 \mathrm{~km}$ (black arrows) on 23 March 2001. Direction changes of this flight are marked by A/B/C. (b) Vertical velocity $\omega$ (color coding; unit: $\mathrm{mb} / \mathrm{s}$ ) for 23 March 2001, calculated using the high-resolution model. (c) Vertical velocity $\omega$ and wind vectors at $2 \mathrm{~km}$ (black arrows) for 23 March 2001, calculated by the coarse-resolution model. 
(a) TRACEP P3B-16 observed and modeled CO

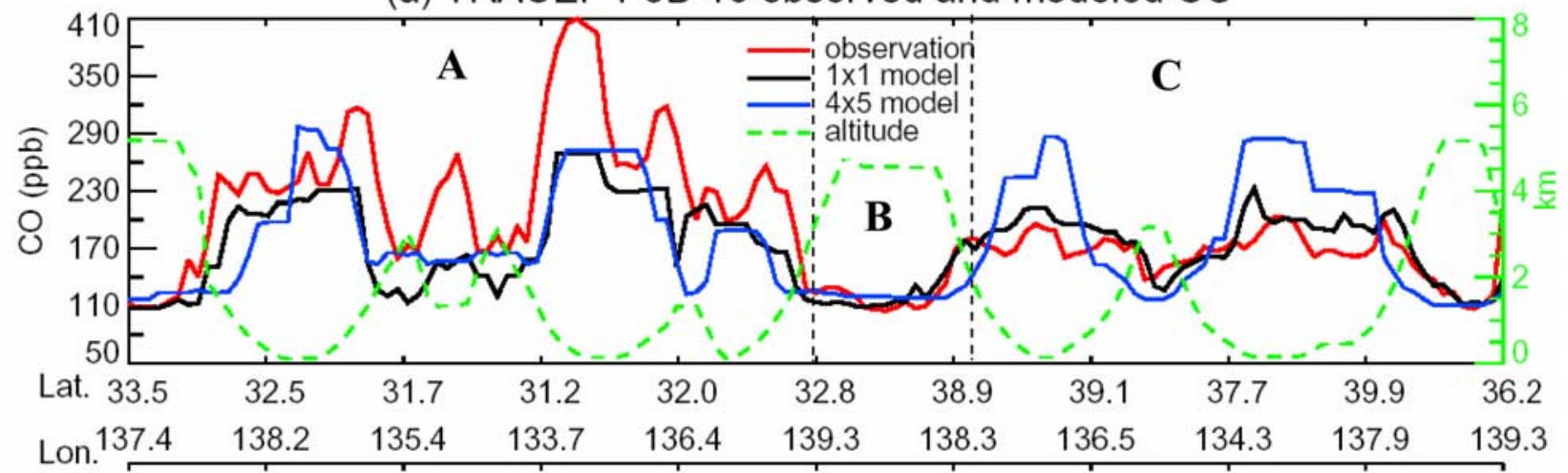

(b) Contributions from tagged tracers

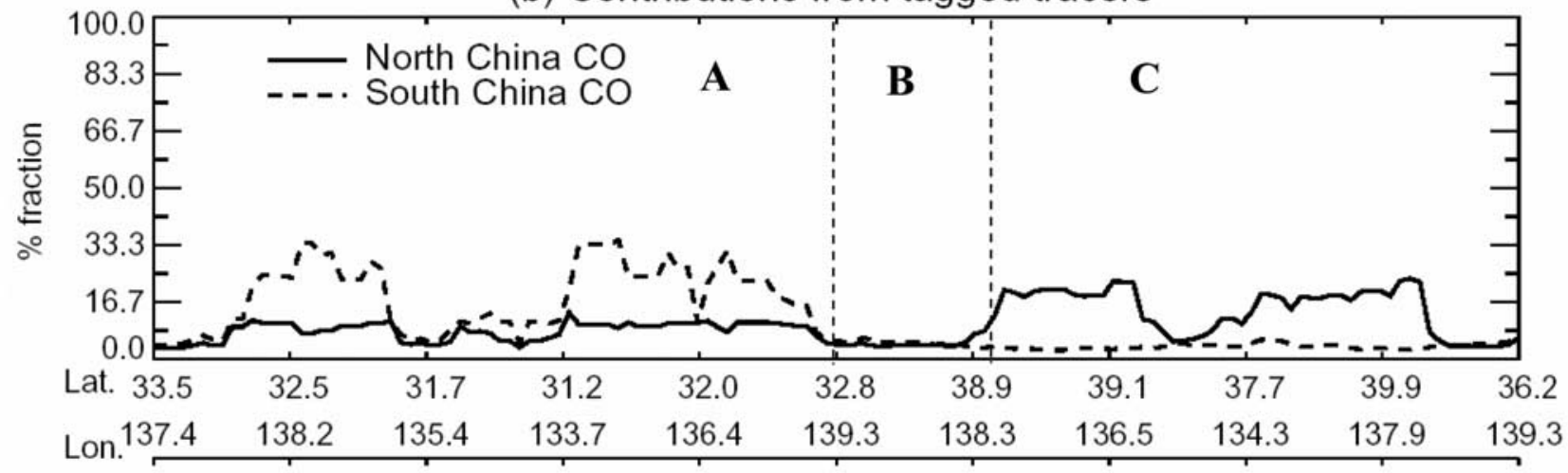

Figure 15. (a) Comparison of CO observations made by P-3B flight 16 (red line) with model results obtained from the high-resolution model (black line) and with model results from the coarse-resolution model (blue line) along flight track of P3B flight 16 on 23 March 2001. Flight altitude is shown by the dashed green line. The $x$ axis is time but labeled in latitude and longitude along the flight track. Direction changes are indicated by $\mathrm{A} / \mathrm{B} / \mathrm{C}$ corresponding to Figure $14 \mathrm{a}$. (b) Simulated percentage contributions from emissions in north China (north of $32^{\circ} \mathrm{N}$ and east of $110^{\circ} \mathrm{E}$ ) (solid black line) and south China (south of $32^{\circ} \mathrm{N}$ and east of $110^{\circ} \mathrm{E}$ ) (dashed black line) along the flight track. 